Article

\title{
Ouabain and Digoxin Activate the Proteasome and the Degradation of the ER $\alpha$ in Cells Modeling Primary and Metastatic Breast Cancer
}

\author{
Claudia Busonero ${ }^{1,+}$, Stefano Leone ${ }^{1,+}{ }^{,}$Fabrizio Bianchi ${ }^{2}\left(\mathbb{D}\right.$, Elena Maspero ${ }^{3}(\mathbb{D}$, \\ Marco Fiocchetti ${ }^{1}$, Orazio Palumbo ${ }^{4}\left(\mathbb{D}\right.$, Manuela Cipolletti ${ }^{1}$, Stefania Bartoloni ${ }^{1}$ and \\ Filippo Acconcia 1,*(D) \\ 1 Department of Sciences, Section Biomedical Sciences and Technology, University Roma Tre, \\ Viale Guglielmo Marconi, 446, I-00146 Rome, Italy; claudia.busonero@uniroma3.it (C.B.); \\ stefano.leone@uniroma3.it (S.L.); marco.fiocchetti@uniroma3.it (M.F.); \\ manuela.cipolletti@uniroma3.it (M.C.); stefania.bartoloni2@uniroma3.it (S.B.) \\ 2 Cancer Biomarkers Unit, Fondazione IRCCS Casa Sollievo della Sofferenza, \\ 71013 San Giovanni Rotondo (FG), Italy; f.bianchi@operapadrepio.it \\ 3 Fondazione Istituto FIRC di Oncologia Molecolare (IFOM), 20139 Milan, Italy; elena.maspero@ifom.eu \\ 4 Division of Medical Genetics, Fondazione IRCCS Casa Sollievo della Sofferenza, \\ 71013 San Giovanni Rotondo (FG), Italy; o.palumbo@operapadrepio.it \\ * Correspondence: filippo.acconcia@uniroma3.it; Tel.: +39-065-733-6320; Fax: +39-065-733-6321 \\ + These authors contributed equally to this work.
}

Received: 25 November 2020; Accepted: 17 December 2020; Published: 19 December 2020

check for updates

Simple Summary: Breast cancer (BC) treatment relies on the detection of the estrogen receptor $\alpha(E R \alpha)$. $\mathrm{ER} \alpha$-expressing $\mathrm{BC}$ patients are treated with anti-estrogen drugs (i.e., tamoxifen and fulvestrant). Despite their proven efficacy, these drugs cause serious side effects in a significant fraction of the patients, including both tumor insurgence in secondary organs, and resistant phenotypes, which result in a relapsing disease with scarce treatment options. Thus, new drugs for treatment of primary and metastatic $\mathrm{BC}(\mathrm{MBC})$ are needed. Here, we report the characterization of two cardiac glycosides (CGs) (i.e., ouabain and digoxin), approved by the FDA for treatment of heart disease, as novel 'anti-estrogen'-like drugs. We found that these drugs induce ER $\alpha$ degradation, and prevent the proliferation of cellular models of primary and metastatic BC cells. Remarkably, we discovered that these CGs are activators of the proteasome, and therefore may be repurposed for treatment not only of $\mathrm{BC}$, but also for other proteasome-based diseases.

\begin{abstract}
Estrogen receptor $\alpha$ expressing breast cancers (BC) are classically treated with endocrine therapy. Prolonged endocrine therapy often results in a metastatic disease (MBC), for which a standardized effective therapy is still lacking. Thus, new drugs are required for primary and metastatic BC treatment. Here, we report that the Food and Drug Administration (FDA)-approved drugs, ouabain and digoxin, induce ER $\alpha$ degradation and prevent proliferation in cells modeling primary and metastatic BC. Ouabain and digoxin activate the cellular proteasome, instigating ER $\alpha$ degradation, which causes the inhibition of $17 \beta$-estradiol signaling, induces the cell cycle blockade in the G2 phase, and triggers apoptosis. Remarkably, these effects are independent of the inhibition of the $\mathrm{Na} / \mathrm{K}$ pump. The antiproliferative effects of ouabain and digoxin occur also in diverse cancer models (i.e., tumor spheroids and xenografts). Additionally, gene profiling analysis reveals that these drugs downregulate the expression of genes related to endocrine therapy resistance. Therefore, ouabain and digoxin behave as 'anti-estrogen'-like drugs, and are appealing candidates for the treatment of primary and metastatic BCs.
\end{abstract}


Keywords: $17 \beta$-estradiol; estrogen receptor; breast cancer; proteasome; ouabain; digoxin

\section{Introduction}

Breast cancer (BC) is the most common cause of cancer-related death among women of all ages worldwide. The most frequent type of $\mathrm{BC}$ is invasive ductal carcinoma, which is estrogen receptor $\alpha$-positive $(\mathrm{ER} \alpha+)$ in most cases (70\%) [1]. 17 $\beta$-Estradiol (E2) signals through the ER $\alpha$ and promotes BC progression via integrated stimulation of transcriptional and non-transcriptional $\mathrm{ER} \alpha$ activity [2]. Thus, the clinical approach for ER $\alpha+$ tumors consists of endocrine therapy [1], aiming to inhibit proliferative E2:ER $\alpha$ signaling. Endocrine therapy drugs either reduce E2 availability (e.g., aromatase inhibitors (AIs)) or block ER $\alpha$ activity by directly binding to the receptor; $4 \mathrm{OH}$-tamoxifen (4OH-Tam), a selective ER modulator (SERM), inactivates ER $\alpha$ transcriptional activity, and fulvestrant (ICI182,780-ICI), a selective ER downregulator (SERD), eliminates $E R \alpha$ from $B C$ cells and prevents receptor transcriptional functions [1]. Thus, endocrine therapy restrains BC progression.

Nonetheless, endocrine therapy has substantial limitations: AIs are typically reserved for postmenopausal women with $\mathrm{BC}$, and produce musculoskeletal failure, while $4 \mathrm{OH}-\mathrm{Tam}$ and ICI have severe side effects (e.g., endometrial cancer for $4 \mathrm{OH}-\mathrm{Tam}$ ), and often cause cell resistance [1]. $4 \mathrm{OH}$-Tam insensitive tumors often still express the $\mathrm{ER} \alpha$, with some of them being resistant at the time of the diagnosis (i.e., de novo resistant), while others acquire $4 \mathrm{OH}-\mathrm{Tam}$ insensitivity during prolonged $4 \mathrm{OH}-\mathrm{Tam}$ treatment through various mechanisms, including the selection of tumor cells that express a mutated constitutively active $\mathrm{ER} \alpha$ variant (e.g., mutation of the receptor tyrosine $(\mathrm{Y}) 537$ into serine (S)) [2-6]. These tumors have proliferative advantages that result in a relapse of the disease and in the recurrence of a metastatic $\mathrm{BC}(\mathrm{MBC})$, for which only limited pharmacological options exist [1].

Consequently, the current challenge is to complement and/or modify the BC drugs available to fight $E R \alpha+$ primary and MBC. Different lines of research are taking place to identify novel SERMs (e.g., basedoxifene) [7] and/or SERDs (e.g., AZD9496 and GDC-9545) [2,8-10], or to identify new pathways that could be targeted alone or in combination with endocrine therapy drugs (e.g., CDK4/CDK6 or CDK7 inhibitors) [2,11-16], especially for MBCs.

Recently, we proposed a strategy to expand the repertoire of effective compounds against ER $\alpha+$ $\mathrm{BC}$ by unveiling a shortcut to rapidly identify new anti-ER $\alpha+\mathrm{BC}$ drugs. In this respect, we introduced the notion that drugs, which do not necessarily bind to ER $\alpha$ but rather change the receptor protein amount in BC cells, can prevent BC cell proliferation and subsequently tumor growth [2]. In turn, we used the ER $\alpha$ levels in BC cells as a novel pharmacological target to screen a library of 1018 Food and Drug Administration (FDA)-approved drugs with the aim of identifying the compounds that can modify ER $\alpha$ protein levels and inhibit BC cell proliferation [2,17-19]. This approach identified medications with potential 'anti-estrogen'-like effects [17-19].

Among those drugs we also identified two cardiac glycosides (CGs), i.e., ouabain-OU and digoxin-Digo [20], as compounds that potentially reduce ER $\alpha$ levels, and prevent cell proliferation in ductal carcinoma cells (MCF-7 cells) [18]. OU and Digo are established plant-derived drugs that inhibit the activity of the $\mathrm{Na} / \mathrm{K}$ ATPase, and are used in the treatment of congestive heart failure (i.e., digitalis treatment) [21].

Here, we evaluated and characterized the effects of these CGs in different models of primary and $\mathrm{MBC}$, and found that $\mathrm{OU}$ and Digo are antiproliferative agents, functioning as small molecule activators of the cellular proteasome. 


\section{Materials and Methods}

\subsection{Cell Culture and Reagents}

17ß-estradiol (E2), DMEM (Dulbecco's Modified Eagle Medium, with and without phenol red), and fetal calf serum were purchased from Sigma-Aldrich (St. Louis, MO, USA). Bradford protein assay kit as well as anti-mouse and anti-rabbit secondary antibodies were obtained from Bio-Rad (Hercules, CA, USA). Antibodies against ER $\alpha$ (F-10 mouse), ubiquitin (Ub) (P4D1 mouse), p53 (DO-1 mouse), Bcl-2 (C2 mouse), cyclin D1 (H-295 rabbit), UBE1 (2G2 mouse), cathepsin D (H75 rabbit), pS2 (FL-84 rabbit), SREBP1 (H160 rabbit) were obtained from Santa Cruz Biotechnology (Santa Cruz, CA, USA); anti-vinculin and anti-tubulin antibodies were purchased from Sigma-Aldrich (St. Louis, MO, USA). Anti-SREBP2 (ab28482 rabbit) was purchased from Abcam (Cambridge, MA, USA). Anti-PARP antibody (95425 rabbit) was purchased by Cell Signaling Technology (Danvers, MA, USA). Chemiluminescence reagent for Western blotting was obtained from BioRad Laboratories (Hercules, CA, USA). Faslodex (i.e., fulvestrant or ICI182,780), AZD9496, GDC-9545, Mg-132 (Mg), and 4OH-tamoxifen (4OH-Tam) as well as the $20 \mathrm{~S}$ recombinant proteasome were purchased from Tocris (USA). All the other products were obtained from Sigma-Aldrich. Analytical- or reagent-grade products were used without further purification. The identities of all the used cell lines (i.e., MCF-7, ZR-75-1, MCF10a-ATTC, LGC Standards S.r.l., Milano, Italy as well as Y537S and Tam Res cells $[2,15,22])$ were verified by STR analysis (BMR Genomics, Padua, Italy).

\subsection{Western Blotting Analyses}

Cells were grown in 10\% serum and DMEM with phenol red, except for the experiments in which E2 was administered. For the E2 experiments, $24 \mathrm{~h}$ before E2 administration, the growth medium was replaced with $1 \%$ charcoal-stripped fetal calf serum medium in DMEM without phenol-red, and cells were left untreated for $24 \mathrm{~h}$. Subsequently, cells were stimulated with E2 at the indicated time points. Cells were lysed in Yoss Yarden (YY) buffer (50 mM HEPES at pH 7.5, 10\% glycerol, $150 \mathrm{mM} \mathrm{NaCl,}$ 1\% Triton X-100, $1 \mathrm{mM}$ EDTA, $1 \mathrm{mM}$ EGTA) plus protease and phosphatase inhibitors, except for PARP detection for which cells were lysed in Tris $\mathrm{HCl} 0.125 \mathrm{M} \mathrm{pH} 6.8$. Western blotting analyses were performed by loading 20-30 $\mu \mathrm{g}$ of protein on SDS-gels. Gels were run and transferred into nitrocellulose membranes with Biorad Turbo-Blot semidry transfer apparatus. Immunoblotting was carried out by incubating membranes with $5 \%$ milk (60 min), followed by overnight incubation with the indicated antibodies. Secondary antibody incubation was performed for an additional $60 \mathrm{~min}$. Bands were detected using a Biorad ChemiDoc ${ }^{\mathrm{TM}}$ apparatus. The original whole blot data is shown in Source data file of Supplementary Materials.

\subsection{Cell Proliferation and Cell Cycle Assays}

For growth curves (Figure 1A,B and Figure S2) and drug synergy studies, the xCELLigence DP system (ACEA Biosciences, Inc., San Diego, CA) Multi-E-Plate station was used to measure the time-dependent response to the indicated drugs, using real-time cell analysis (RTCA), as previously reported $[23,24]$. Briefly, the number of cells (i.e., normalized cell index) is directly proportional to the measured electric impedance of the cells on the well surface. MCF-7, ZR-75-1, Tam Res, and Y537S ER $\alpha$-expressing MCF-7 (Y537S) cells were seeded in E-Plates 96 in growth media. After overnight monitoring of growth at 15 min intervals, drugs were added according to the following protocol: 4OH-tamoxifen, fulvestrant (ICI182,780), AZD9496 and GDC-9545 at 10, 100, 1000, 100,000 nM separately, or in combination with ouabain or digoxin at concentrations of 30, 60, 100, $250 \mathrm{nM}$. Cells remained in the medium until the end of the experiment. Cellular responses were then recorded every $15 \mathrm{~min}$, for a total period of 5 days. Next, synergy index was calculated with Combenefit freeware software [25]. The normalized cell index at 5 days for the combination of drugs at the lowest dose that exhibited a synergistic effect on cell proliferation was obtained, and is presented in Figure 9A,B. 
A

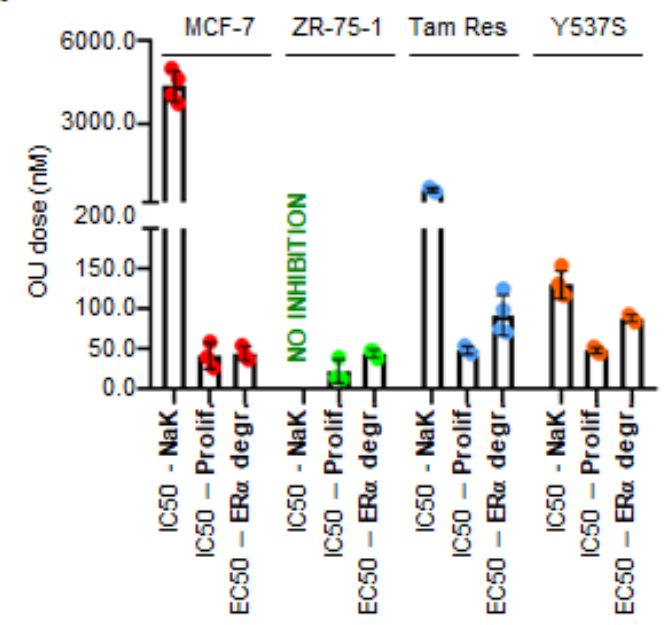

C
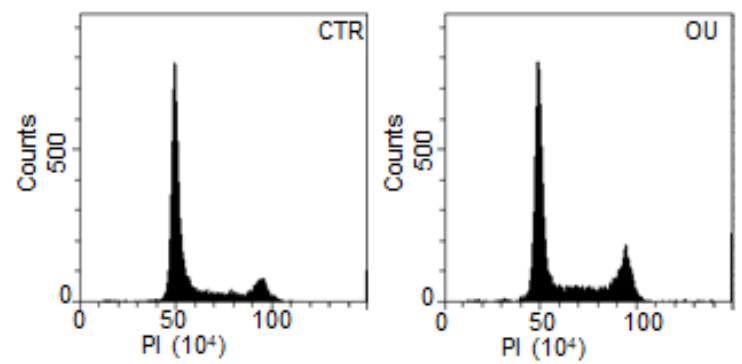

B

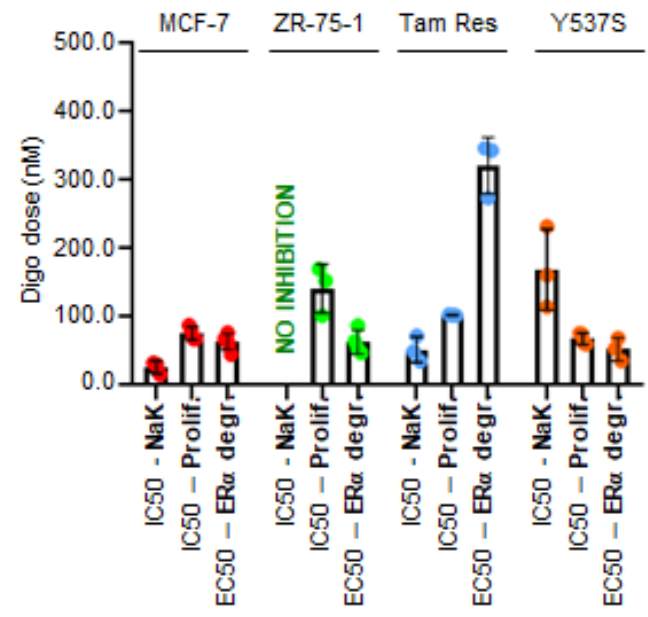

C'
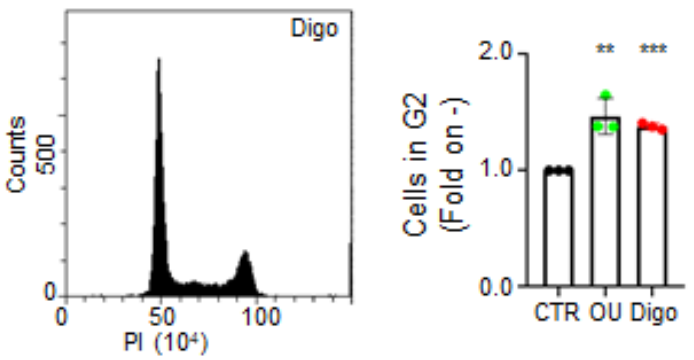

$\mathbf{F}$

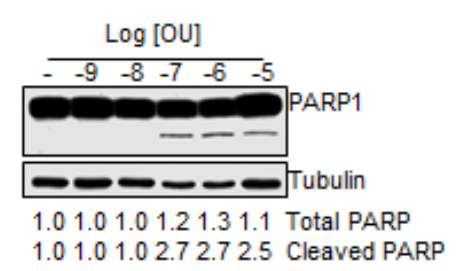

E

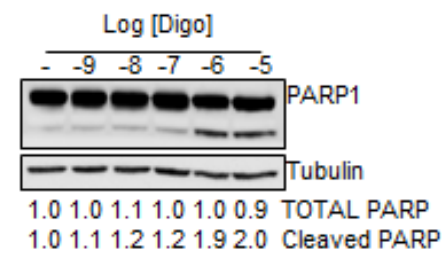

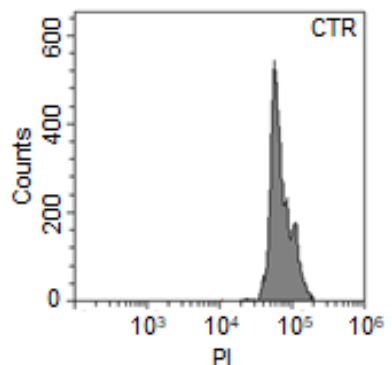

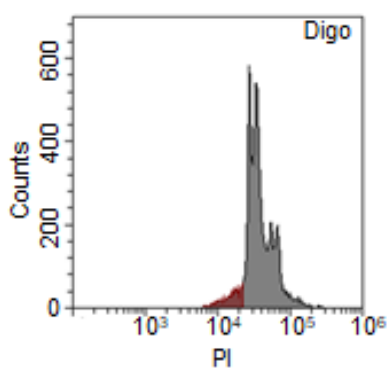

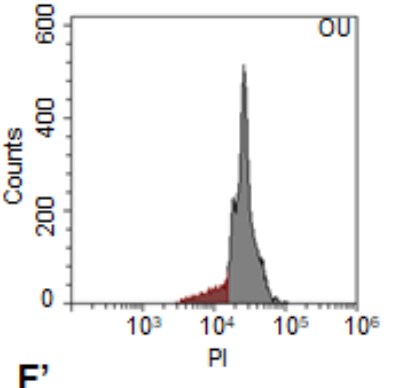

F'

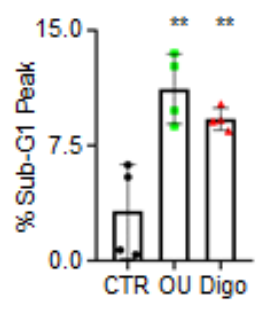

Figure 1. Effective concentrations analysis of the ouabain and digoxin effects on ER $\alpha$ expression, cell proliferation, and $\mathrm{Na} / \mathrm{K}$ ATPase activity in breast cancer cells. (A) Effective dose $50\left(\mathrm{ED}_{50}-\mathrm{nM}\right)$ of ouabain (OU) for reduction in ER $\alpha$ intracellular levels in the indicated cell lines, calculated after $24 \mathrm{~h}$ of drug administration to each cell line; inhibitor concentration $50\left(\mathrm{IC}_{50}-\mathrm{nM}\right)$ of $\mathrm{OU}$ for cell proliferation in the indicated cell lines, calculated after 5 days of treatment for each cell line; $\mathrm{IC}_{50}(\mathrm{nM})$ for OU for Na/K ATPase activity in the indicated cell lines, calculated after $24 \mathrm{~h}$ of treatment for each cell line. (B) $\mathrm{ED}_{50}(\mathrm{nM})$ 
of digoxin (Digo) for the reduction in ER $\alpha$ intracellular levels in the indicated cell lines, calculated after $24 \mathrm{~h}$ of drug administration to each cell line; $\mathrm{IC}_{50}(\mathrm{nM})$ of Digo for cell proliferation in the indicated cell lines, calculated after 5 days of treatment for each cell line, and $\mathrm{IC}_{50}(\mathrm{nM})$ of Digo for Na/K ATPase activity in the indicated cell lines, calculated after $24 \mathrm{~h}$ of treatment for each cell line. Cell cycle analysis (C) and relative quantitation of the G2 phase $\left(\mathbf{C}^{\prime}\right)$ in ZR-75-1, treated for $24 \mathrm{~h}$ with either ouabain (OU-100 nM), or digoxin (Digo-1000 nM), and for untreated cells (CTR). Significant differences with respect to the CTR sample were obtained by unpaired two-tailed Student's $t$-test: ${ }^{* * *} p<0.001$; ** $p<0.01$. Western blotting analyses of PARP1 expression levels in ZR-75-1 cells, treated for $24 \mathrm{~h}$ with ouabain (OU) (D), and digoxin (Digo) (E) at the indicated doses. The loading control was performed by evaluating tubulin expression in the same filter. Experiments were performed twice in duplicates. Cell cycle analysis $(\mathbf{F})$ and relative quantitation $\left(\mathbf{F}^{\prime}\right)$ for the evaluation of the sub-G1 phase in ZR-75-1, treated for $72 \mathrm{~h}$ with ouabain (OU-100 nM), or digoxin (Digo-1000 nM), or untreated (CTR). Experiments were performed four times. Significant differences with respect to the CTR sample were obtained by unpaired two-tailed Student's $t$-test: ${ }^{* *} p<0.01$.

For cell cycle analysis, after each treatment, $1 \times 10^{6}$ cells were washed twice with PBS, fixed dropwise with ice cold ethanol (70\%), and rehydrated with PBS. DNA staining was performed by incubating cells for $30 \mathrm{~min}$ at $37^{\circ} \mathrm{C}$ in PBS, containing $0.18 \mathrm{mg} / \mathrm{mL}$ propidium iodide (PI) and $0.4 \mathrm{mg} / \mathrm{mL}$ DNase-free RNase (type 1-A). Samples were measured with a CytoFlex Flow Cytometer (Beckman Coulter). Cell cycle analysis was performed using a CytExpert v.2.4 software (Beckman Coulter). Doublet discrimination was performed by an electronic gate on FL3-Area vs. FL3-Height parameters. For hypodiploid peak analysis, Nicoletti's protocol was followed [26]. Briefly, cell pellet was resuspended in $500 \mu \mathrm{L}$ of PBS $+500 \mu \mathrm{L}$ of hypotonic staining solution $(0.1 \%$ sodium citrate $(w / v)$, $0.1 \%$ Triton $\mathrm{X}-100(v / v), 50 \mu \mathrm{g} / \mathrm{mL}$ propidium iodide, $\mathrm{pH} 7.8)$. Cells were incubated for $30 \mathrm{~min}$ at room temperature. Finally, 20,000 total events, presented in a logarithmic scale were acquired directly in the staining buffer, and percentage of the hypodiploid peak was calculated by a proper electronic marker.

\subsection{Measurement of Proteasome Activity}

Proteasome activity was measured by employing the Proteasome-Glo ${ }^{\mathrm{TM}}$ Assay Kit for chymotrypsin-, trypsin-, and caspase-like activities, purchased from Promega (Madison, MA, USA). Each one of the following experiments was performed at least in triplicates. Briefly, for measurements of proteasome activity in cells, the indicated cell lines were seeded in 96-well plates (10,000 cells/well; each condition in triplicates) in growth media, for $24 \mathrm{~h}$. Next, cells were treated with different doses of ouabain, digoxin, or equal quantities of vehicle (DMSO) only for digoxin, for an additional 8 or $24 \mathrm{~h}$. Notably, the proteasome inhibitor Mg-132 $(1 \mu \mathrm{M})$ was used as internal control for all assays. After treatment, the three activities of the proteasome were measured according to manufacturer's instructions, in a Tecan-Spark Elisa reader every other $30 \mathrm{~s}$, for a total period of $30 \mathrm{~min}$. For in vitro measurements of proteasome activity, $30 \mu \mathrm{g}$ of recombinant $20 \mathrm{~S}$ proteasome (Boston Biochem, Boston, MA, USA) was placed in contact with ouabain alone, or in the presence of different doses of the proteasome inhibitor Mg-132 (the doses for calculating the inhibitor concentration $50\left(\mathrm{IC}_{50}\right)$ were adjusted for each activity, according to previously reported data [27]), immediately before measuring the three activities of the proteasome. This was done according to the kit manufacturer's instructions, in a Tecan-Spark Elisa reader set at $37^{\circ} \mathrm{C}$, every other $30 \mathrm{~s}$ for a total period of $30 \mathrm{~min}$. The data obtained within the first $10 \mathrm{~min}$ of the measurements were used for this study.

\subsection{Measurement of Na/K ATPase Activity}

Cells were seeded in 96-well plates (10,000 cells/well; each condition in a quadruplicate) in growth media for $24 \mathrm{~h}$. After $24 \mathrm{~h}$, the $\mathrm{Na} / \mathrm{K}$ ATPase assay was performed as previously reported [28]. Briefly, cells were washed with $\mathrm{NaCl}(0.9 \%)$ and lysed in $\mathrm{ddH}_{2} \mathrm{O}$. Then, cells were incubated for $10 \mathrm{~min}$ at $37^{\circ} \mathrm{C}$ in Assay Buffer 2× $\left(36 \mathrm{mM}\right.$ histidine, $36 \mathrm{mM}$ imidazole, $160 \mathrm{mM} \mathrm{NaCl}, 30 \mathrm{mM} \mathrm{KCl}, 6 \mathrm{mM} \mathrm{MgCl}_{2}$, $0.2 \mathrm{mM}$ EGTA, pH 7.1) in the presence or absence of different doses of ouabain $\left(10^{-9}\right.$ to $\left.10^{-2} \mathrm{M}\right)$, digoxin 
$\left(10^{-9}\right.$ to $\left.10^{-4} \mathrm{M}\right)$, or equal quantities of vehicle (DMSO) only for digoxin, for an additional $24 \mathrm{~h}$. Next, $1 \mathrm{mM}$ ATP was added to the reaction mixture, and the plates were incubated for $24 \mathrm{~h}$ at $37^{\circ} \mathrm{C}$ in $5 \%$ $\mathrm{CO}_{2}$. The following day, the reaction was blocked using $25 \mu \mathrm{L} /$ well of SDS 5\%, and $125 \mu \mathrm{L} /$ well of colorimetric solution (ammonium molybdate $/ \mathrm{H}_{2} \mathrm{SO}_{4}$ followed by ascorbic acid) was added, in order to measure the concentration of free $P_{i}$ in each sample. The Na/K ATPase activity was derived by subtracting the activity measured in the presence of ouabain from the total activity. Numeric values of absorbance were obtained with a Tecan-Spark Elisa reader, with the wavelength set at $630 \mathrm{~nm}$. All experiments were performed at least in triplicates.

\subsection{ER $\alpha$ Binding Assay}

A fluorescence polarization (FP) assay was used to measure ouabain, digoxin, and $17 \beta$-estradiol binding affinity to recombinant $\mathrm{ER} \alpha$ in vitro as previously described [29].

\subsection{RNA Isolation and $q P C R$ Analysis}

The sequences for gene-specific forward and reverse primers were designed using the OligoPerfect Designer software program (Invitrogen, Carlsbad, CA, USA). The primers used for human ER $\alpha$ were $5^{\prime}$-GTGCCTGGCTAGAGATCCTG-3' (forward) and 5'-AGAGACTTCAGGGTGCTGGA-3' (reverse), and for human GAPDH were 5'-CGAGATCCCTCCAAAATCAA-3' (forward) and 5'-TGTGGTCATGAGTCCTTCCA-3' (reverse). Total RNA was extracted from the cells using TRIzol Reagent (Invitrogen, Carlsbad, CA, USA), according to the manufacturer's instructions. To determine gene expression levels, cDNA synthesis and qPCR were performed using the GoTaq 2-step RT-qPCR system (Promega, Madison, MA, USA), with an ABI Prism 7900HT Sequence Detection System (Applied Biosystems, Foster City, CA, USA), according to the manufacturer's instructions. Each sample was tested in triplicates, the experiment was repeated twice, and gene expression was normalized to GAPDH mRNA levels.

\subsection{Affimetrix Analysis}

Total RNA was extracted using RNeasy kit (Qiagen, Hilden, Germany), according to manufacturer's protocol, and was quantified using a NanoDrop 2000 system (Thermo Scientific, Waltham, MA, USA). A GeneChip Pico Reagent Kit (Affymetrix, Santa Clara, CA, USA) was used to amplify 5 ng of total RNA, according to the manufacturer's protocol. Quality control of the RNA samples was performed using an Agilent Bioanalyzer 2100 system (Agilent Technologies, Santa Clara, CA, USA). Gene expression profiling was performed using the Affymetrix GeneChip ${ }^{\circledR}$ Human Clariom S Array (Thermo Fisher Scientific), including more than 210,000 distinct probes representative of 21,448 annotated genes (hg19; Genome Reference Consortium Human Build 37 (GRCh37); https:/www.ncbi.nlm.nih.gov/assembly/GCF_000001405.13/). RNA samples were amplified, fragmented, and labeled for array hybridization according to manufacturer's instruction. Samples were then hybridized overnight, washed, stained, and scanned using the Affymetrix GeneChip Hybridization Oven 640, Fluidic Station 450 and Scanner 3000 7G (Thermo Fisher Scientific), to generate raw data files (.CEL files). Quality control and normalization of Affymetrix. CEL files were performed using the TAC software (v4.0; Thermo Fisher Scientific), by performing the "Gene level SST-RMA" summarization method with human genome version hg38 (https: //www.ncbi.nlm.nih.gov/assembly/GCF_000001405.26/). Gene expression data were log2 transformed before analyses. Class comparison analysis for identifying differentially regulated genes was performed using a t-test with a random variance model and 1000 random data permutations to compute the local false discovery rate (FDR or $q$-value). An FDR $<0.05$ was used as cutoff for significantly regulated gene selection. Hierarchical clustering and heatmaps analyses were performed using Cluster 3.0 (http://bonsai.hgc.jp/ mdehoon/software/cluster/software.htm) and Java Tree View (http://jtreeview.sourceforge.net). The uncentered correlation and centroid linkage clustering method was adopted. Ingenuity pathway analysis (IPA; QIAGEN, Hilden, Germany) was performed to identify 
canonical pathways enriched in ouabain/digoxin regulated genes. Significantly enriched pathways were defined as those with a $q$-value (Benjiamini and Hochberg correction) of less than 0.05. IPA was also used to perform Upstream Regulator analysis for identification of upstream transcriptional regulators (TR) that can explain the observed changes in gene expression. Briefly, for each potential TR, two statistical measures, an overlap $p$-value and an activation z-score are computed. The overlap $p$-value calls potential TR, based on significant overlap between the set of genes (i.e., ouabain/digoxin regulated) and known targets regulated by a TR. The activation z-score is used to infer likely activation states of TR, based on comparison with a model that assigns random regulation directions.

\subsection{Dot Blot Analysis}

For dot blot analyses, cells were treated as described above, and subsequently harvested and lysed in YY buffer. Lysates (10-15 $\mu \mathrm{g}$ ) were diluted in a final volume of $100 \mu \mathrm{L}$ with YY buffer, and mechanically transferred onto a nitrocellulose membrane with a Bio-Dot ${ }^{\circledR}$ Microfiltration apparatus (Biorad). The filter was then stained with Ponceau Red staining (Sigma-Aldrich), de-stained with $\mathrm{ddH}_{2} \mathrm{O}$, and the resulting image was acquired with a digital scanner. Next, the nitrocellulose membrane was treated as a regular Western blotting (see above).

\subsection{Tumor Spheroid Formation}

Tumor spheroid formation was performed as previously reported [30]. Briefly, MCF-7 and Y537S ER $\alpha$-expressing MCF-7 (Y537S) cells were seeded (10,000 cells/well) in ultra-low attachment surface 24-well-plates (Sigma-Aldrich), with $1 \mathrm{~mL} /$ well in growing condition, for $48 \mathrm{~h}$. Next, using an optical microscope, images were obtained for each untreated well (i.e., prior to treatment, time 0). Next, cells were treated in quadruplicate with ICI182,780 (100 nM), ouabain (100 nM), digoxin (100 nM), and with vehicle (DMSO). After $48 \mathrm{~h}$, the cell culture medium was replaced, using a $70 \mu \mathrm{m}$ nylon sterile cell strainer for each condition, in order to maintain spheroids with a diameter greater than $70 \mu \mathrm{m}$, and to remove dead cells and spheroids with diameters smaller than $70 \mu \mathrm{m}$. Subsequently, the treatment was repeated. Seven days post initial drug administration, images were obtained for each well. Number of spheroids was quantitated using the freeware software Image J.

\subsection{Transthiolation Assay}

Thioester formation was performed in two steps. First, an incubation reaction was performed using Ube2D3 (4 $\mu \mathrm{M})$, biotinylated Ub (8 $\mu \mathrm{M}$ BML-UW8705, Enzo Lifescience, Ann Arbor, MI, USA), and $E_{1}$ enzyme $(150 \mathrm{nM})$, for $2 \mathrm{~h}$ at room temperature in ubiquitination buffer, in the presence and in the absence of OU at the indicated concentrations. In the second step, ATP $(4 \mathrm{mM})$ was added to the reaction, and the mix was moved to $37^{\circ} \mathrm{C}$. Thioester formation on the $E_{1}$ and $E_{2}$ was monitored by quenching the reaction after $15 \mathrm{~min}$ with Laemmli buffer, with and without a reducing agent (DTT, $100 \mathrm{mM}$ ). Samples were loaded on gradient gel (4-20\% Biorad), transferred to a nitrocellulose membrane, and detection was obtained by immunoblot, using HRP conjugated streptavidin (Thermo Scientific).

\subsection{Zebrafish Xenografts}

Zebrafish xenograft experiments were performed by ZeClinics (Barcelona, Spain) according to the procedure published in [31], with modifications in image analysis to allow measurement of the tumor area, rather than tumor volume. Briefly, Casper adult Zebrafish (Danio Rerio) were mated to obtain embryos. The study was performed under the ethical approval code 10567, provided by the Generalitat of Catalunya. Forty-eight hours post fertilization, larvae were injected with 200-400 Y573S cells in the perivitelline space. An hour later, noninjected and nonspecifically injected larvae were discarded. For the experiment in Figure 9D, xenografts were imaged at timepoint 0 (i.e., 24 h post injection) and at time point 2 (i.e., $96 \mathrm{~h}$ post injection and 3 days drug treatment). Tumor development was evaluated by comparing the cell masses and dissemination between time point 0 and time point 4 for each larva. Ratio of areas between timepoints 0 and 2 were calculated for each larva and mean 
primary tumor areas average fold change between the two time points was calculated both for controland drug-treated groups. The relative final report containing the details of the procedure used and the relative analysis is available to share upon reasonable request.

\subsection{Statistical Analysis}

A statistical analysis was performed using the InStat version 8 software system (GraphPad Software Inc., San Diego, CA). Densitometric analyses were performed using the freeware software Image J, by quantifying the band intensity of the protein of interest with respect to the relative loading control band (i.e., vinculin or tubulin) intensity. The $p$ values and the applied statistical test are provided in the figure captions.

\section{Results}

\subsection{Evidence of Na/K ATPase-Independent Effects of Ouabain and Digoxin in Breast Cancer Cells}

OU and Digo dose response curves were obtained to find both the effective dose $50\left(\mathrm{ED}_{50}\right)$ required to reduce $\mathrm{ER} \alpha$ content, and the inhibitor concentration $50\left(\mathrm{IC}_{50}\right)$ required to prevent cell proliferation. The experiments were performed in cell lines modeling either primary ER $\alpha+$ breast tumors sensitive to 4OH-Tam (i.e., MCF-7 and ZR-75-1 cells) or modeling metastatic tumors with acquired resistance to 4OH-Tam (i.e., 4OH-Tam resistant MCF-7 cells-Tam Res) [22] or with genetic resistance to endocrine therapy drugs (i.e., MCF-7 cells CRISPR/CAS9 engineered to express the Y537S ER $\alpha$ point mutant-Y537S) [2,15]. In all tested cell lines, both OU and Digo induced ER $\alpha$ degradation within $24 \mathrm{~h}$, in a dose-dependent manner with a calculated $\mathrm{ED}_{50}$ in the range of 50-100 $\mathrm{nM}$ for OU, and 50-400 nM for Digo (Figure 1A,B and Figure S1). In addition, OU and Digo reduced the proliferation of $\mathrm{BC}$ cells in a cell type specific manner, with a calculated $\mathrm{IC}_{50}$ at 5 days for OU of $\approx 50 \mathrm{nM}$, and 60-200 nM for Digo (Figure 1A,B and Figure S2). These data confirm that OU and Digo induce $\mathrm{ER} \alpha$ degradation, and prevent proliferation in cells modeling primary and $4 \mathrm{OH}$-Tam resistant $\mathrm{BC}$ cells.

As OU and Digo inhibit the $\mathrm{Na} / \mathrm{K}$ ATPase enzyme [21], we next examined whether the reduction in $\mathrm{ER} \alpha$ intracellular levels could be attributed to a blockade of the $\mathrm{Na} / \mathrm{K}$ pump activity in BC cells. Thus, we measured the $\mathrm{Na} / \mathrm{K}$ ATPase activity in all the above-mentioned $\mathrm{BC}$ cells in the presence of various doses of OU and Digo, for $24 \mathrm{~h}$. Surprisingly, while, as expected, the CGs inhibited the $\mathrm{Na} / \mathrm{K}$ ATPase activity in all tested cell lines [21], they did not inhibit the activity of the $\mathrm{Na} / \mathrm{K}$ pump in the ZR-75-1 (Figure 1A,B). Moreover, we noticed that the $\mathrm{IC}_{50}$ for the inhibition of the Na/K ATPase enzyme for OU was higher in all BC cells than both the $\mathrm{ED}_{50}$ required to reduce $\mathrm{ER} \alpha$ content, and the $\mathrm{IC}_{50}$ required to prevent cell proliferation (Figure $\left.1 \mathrm{~A}, \mathrm{~B}\right)$. The same phenomenon was observed for Digo in Y537S, but not in MCF-7 and Tam Res cells (Figure 1A,B). Therefore, these data, together with the insensitivity of the $\mathrm{Na} / \mathrm{K}$ pump to both OU and Digo, expressed in ZR-75-1 cells, suggest that the observed OU and Digo effects on ER $\alpha$ levels and cell proliferation in BC cells do not occur entirely in parallel with the inhibition of $\mathrm{Na} / \mathrm{K}$ ATPase enzyme.

To further investigate this issue, we used the ZR-75-1 cells in which the $\mathrm{Na} / \mathrm{K}$ ATPase enzyme was not inhibited by OU and Digo. In this cell line, we performed cell cycle analysis, and measured the apoptotic induction after treatment with different doses of OU and Digo. As shown in Figure $1 C, C^{\prime}$, the CGs increased the percentage of the cells in the G2 phase of the cell cycle in ZR-75-1 cells, as well as in other BC cells, within $24 \mathrm{~h}$ (Figure S3). In line with the observed CGs-induced blockade in the G2 phase of the cell cycle, treatment of ZR-75-1 cells with OU and Digo for $72 \mathrm{~h}$ induced a significant increase in the abundance of the cleaved PARP (Figure 1D,E), and in the sub-G1 phase of the cell cycle (Figure $1 \mathrm{~F}, \mathrm{~F}^{\prime}$ ). 
Therefore, OU and Digo reduce ER $\alpha$ levels, and establish a cell cycle block in the G2 phase, accompanied by an induction of apoptotic cell death. Remarkably, these effects occur independently of the inhibition of the Na/K ATPase enzyme in ZR-75-1 cells.

\subsection{The Ouabain and Digoxin Impact on the Proteasome in Breast Cancer Cells}

In order to identify molecular mechanisms impinged by OU and Digo, which are relevant for both the degradation of the ER $\alpha$ and for proliferation of cells modeling primary and $\mathrm{MBC}$, we performed Affymetrix gene expression profile of MCF-7, Tam Res, and Y537S cells treated for $24 \mathrm{~h}$ with either OU or Digo (100 nM). Notably, we chose to treat cells with the same concentration for either CG to avoid any technical bias due to different drug concentration.

Gene expression profile analysis revealed that OU treatment in all BC cells significantly modulated 2226 genes ( $q$-value $<0.05$ ) (Table S1), while Digo treatment modulated 2153 genes $(q$-value $<0.05)$ in all BC cells (Table S2), with a significant overlap between the two gene sets, of 1328 genes ( $p$-value < 0.0001; Fisher's test). The substantial overlap between OU- and Digo-regulated genes further suggests a common mechanism of action of the two drugs in $\mathrm{BC}$ cells.

Ingenuity pathway analysis (IPA) confirmed common, significantly represented pathways ( $q$-value $<0.05)$ among OU- and Digo-regulated genes, with the top three pathways related to 'protein ubiquitination', 'tRNA charging', and 'cholesterol biosynthesis' (Tables S3 and S4). Moreover, IPA upstream regulator analyses for the CGs-modulated genes predicted the common inactivation of a variety of transcription factors (e.g., SREBP2, NRF2, SOX11, TBX2) (Tables S5 and S6). Accordingly, Western blotting analysis confirmed that in MCF-7 and in Y537S cells, OU and Digo reduced the protein expression of both SREBP2 and of SREBP1, which is the other human sterol regulatory element-binding protein (Figure S4A,B).

We additionally studied the impact of OU and Digo on the ubiquitination pathway (i.e., ubiquitination cascade and proteasome) in $\mathrm{BC}$ cells. Dose response curves were performed to evaluate the total ubiquitinated species in MCF10a, MCF-7, ZR-75-1, Y537S, and Tam Res cells. Figure $2 \mathrm{~A}-\mathrm{L}$ demonstrates that $\mathrm{OU}$ and Digo reduce the total content of ubiquitinated species in a dose-dependent manner, depending on the cell type, with a dramatic effect observed between $10^{-7}$ and $10^{-6} \mathrm{M}$, with the exception of MCF10a. These data support the notion that these CGs deregulate the proteasome/ubiquitination pathway.

Next, we speculated that the CGs could influence the activity of the ubiquitin-activating enzyme $\left(E_{1}\right)$, since it has been previously demonstrated that its inhibition leads to a reduction in total ubiquitinated species [32,33]. Therefore, we measured the activity of $E_{1}$ in the presence and absence of $\mathrm{OU}$ in in vitro ubiquitination assays [34]. Figure $2 \mathrm{M}$ shows that preincubation of $\mathrm{E}_{1}$ with different concentrations of $\mathrm{OU}$ did not affect its ability to form thioester bonds with $\mathrm{Ub}$ on their catalytic cysteine. Thus, OU was not able to inhibit the $\mathrm{E}_{1}$ activity in vitro. Despite this evidence, we speculated that the reduction in total ubiquitinated species in the cells could also be dependent on a reduction in the intracellular content of the $E_{1}$ enzyme. Therefore, we measured the levels of UBE1 (i.e., $E_{1}$ ) in both MCF-7 and ZR-75-1 cells treated with different doses of OU and Digo for $24 \mathrm{~h}$, and observed that the CGs do not change the UBE1 intracellular levels (Figure 2N,N'). Therefore, OU does not affect the activity of the $\mathrm{E}_{1}$ enzyme, and neither one of the CGs significantly changes the $\mathrm{E}_{1}$ levels.

These data indicate that $\mathrm{OU}$ and Digo reduce the total protein ubiquitination levels in a dose-dependent manner in various BC cell lines, but not in non-transformed breast MCF10a cells. This effect is not attributed to either an inhibition of the in vitro activity of the $E_{1}$, nor to a significant modification of the $\mathrm{E}_{1}$ intracellular levels. 
A

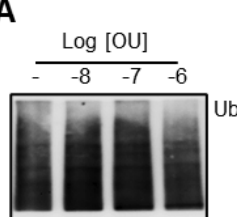

- - - Vinculin

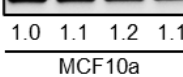

C

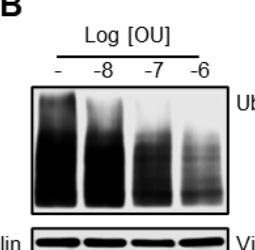

$\begin{array}{llll}1.0 & 0.9 & 0.8 & 0.5\end{array}$

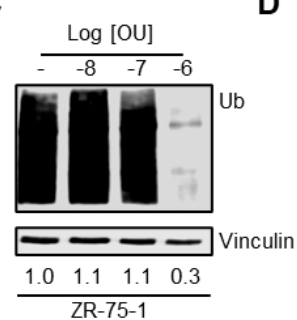

D

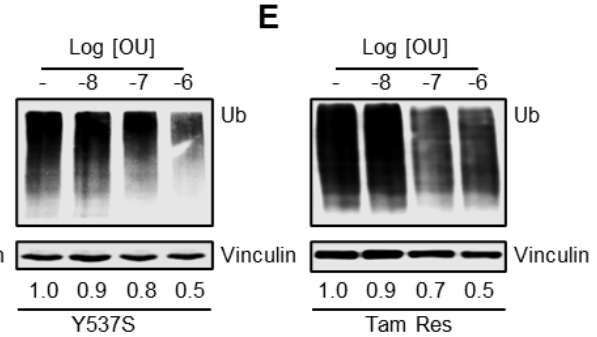

F

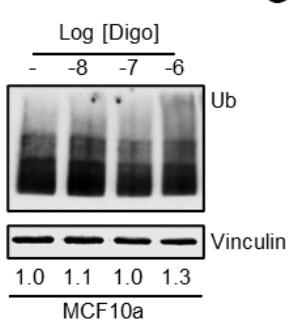

G

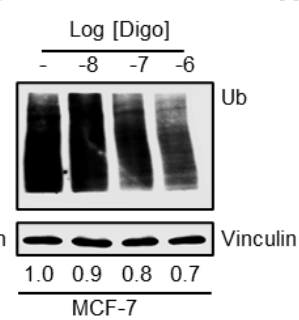

H

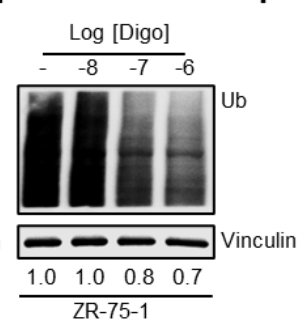

I

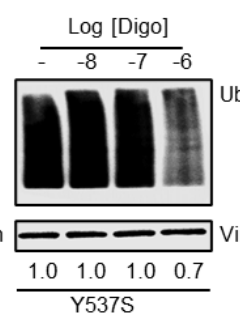

L

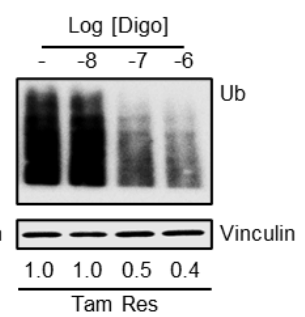

M

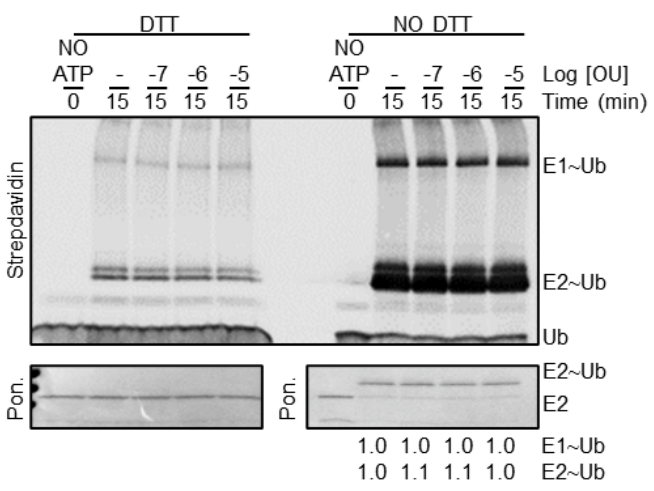

$\mathbf{N}$

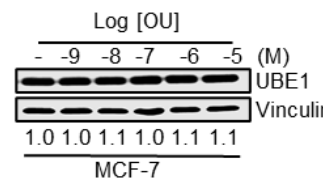

N'

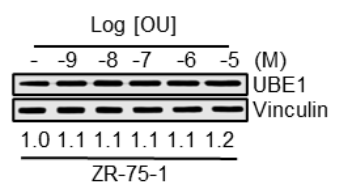

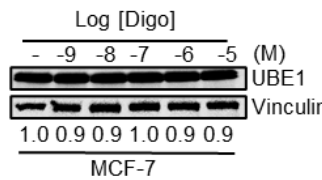

Log [Digo]

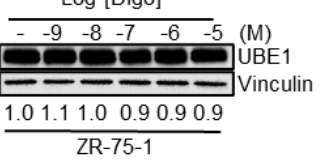

Figure 2. The effect of ouabain and digoxin on the ubiquitin-proteasome pathway. Western blotting analyses of ubiquitin $(\mathrm{Ub})$ expression in the indicated cell lines, treated for $24 \mathrm{~h}$ with the indicated doses of ouabain (OU) (A-E), and digoxin (Digo) (F-L). Experiments were repeated three times. (M) Western blotting analyses of streptavidin-detected ubiquitin-activating $\left(\mathrm{E}_{1}\right)$ and ubiquitin-conjugating $\left(\mathrm{E}_{2}\right)$ enzyme-dependent biotinylated $\mathrm{Ub}(\mathrm{Ub})$ thioester formation, in the presence of the indicated doses of ouabain (OU), for $15 \mathrm{~min}$. The transfer of $\mathrm{Ub}$ to $\mathrm{E}_{1}\left(\mathrm{E}_{1} \sim \mathrm{Ub}\right)$ and $\mathrm{E}_{2}\left(\mathrm{E}_{2} \sim \mathrm{Ub}\right)$ was monitored by quenching the reaction by addition of Laemmli buffer, with and without the reducing agent $(100 \mathrm{mM}$ DTT). Right panel (without DTT-NO DTT) indicates thioester loaded $E_{1}\left(E_{1} \sim U b\right)$ and $E_{2}\left(E_{2} \sim U b\right)$. Left panel (DTT-resistant bands-DTT) represents self-ubiquitinated enzymes. Ponceau (Pon.) staining of the membrane after transfer was used to show equal loading of the enzymes in all samples, both in the presence and in the absence of ATP (NO ATP-0). Experiments were performed twice. Western blotting analyses of the ubiquitin-activating enzyme (UBE1) expression in MCF-7 (N) and ZR-75-1(N') cells, treated for $24 \mathrm{~h}$ with the indicated doses of ouabain (OU), digoxin (Digo), and untreated (-). Experiments were performed twice.

Nevertheless, as hierarchical clustering analysis returned a large OU- and Digo-dependent downregulation of genes encoding for the proteasome subunits (Figure 3A,B, and Table S7), we evaluated whether OU and Digo could affect proteasomal function. For that purpose, we initially investigated the effect of the CGs in MCF-7 and ZR-75-1 cells in the presence and in the absence of the proteasome inhibitor $\mathrm{Mg}-132$, in order to evaluate the overall proteasome-degradation functions, using p53, a protein well-known for being targeted by the proteasome for degradation [35]. 
A

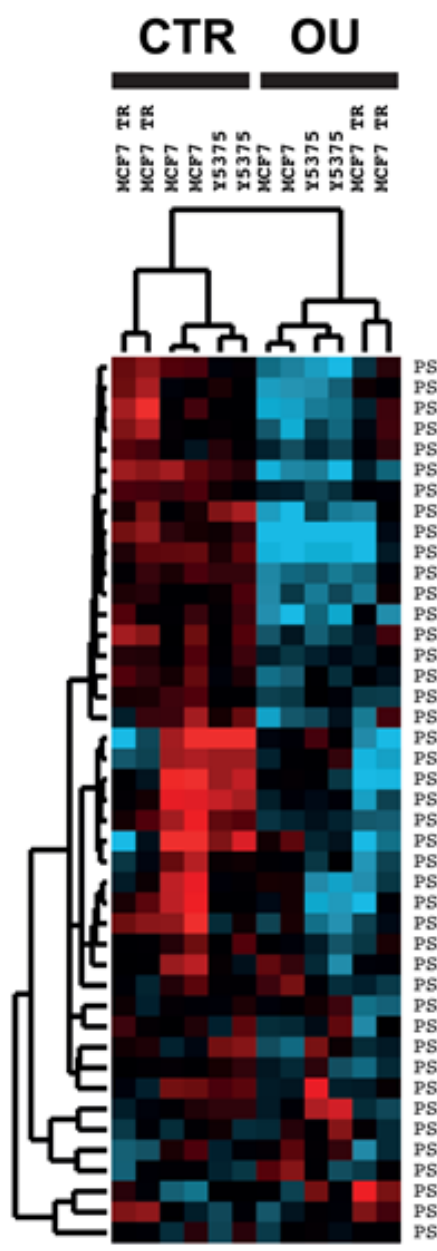

C

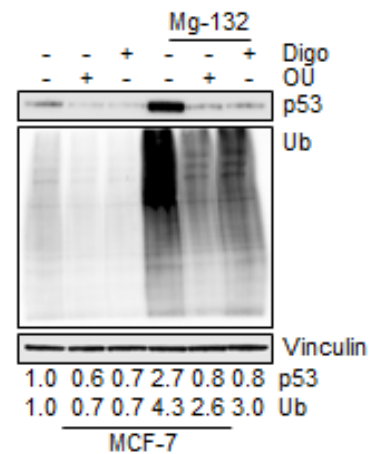

B
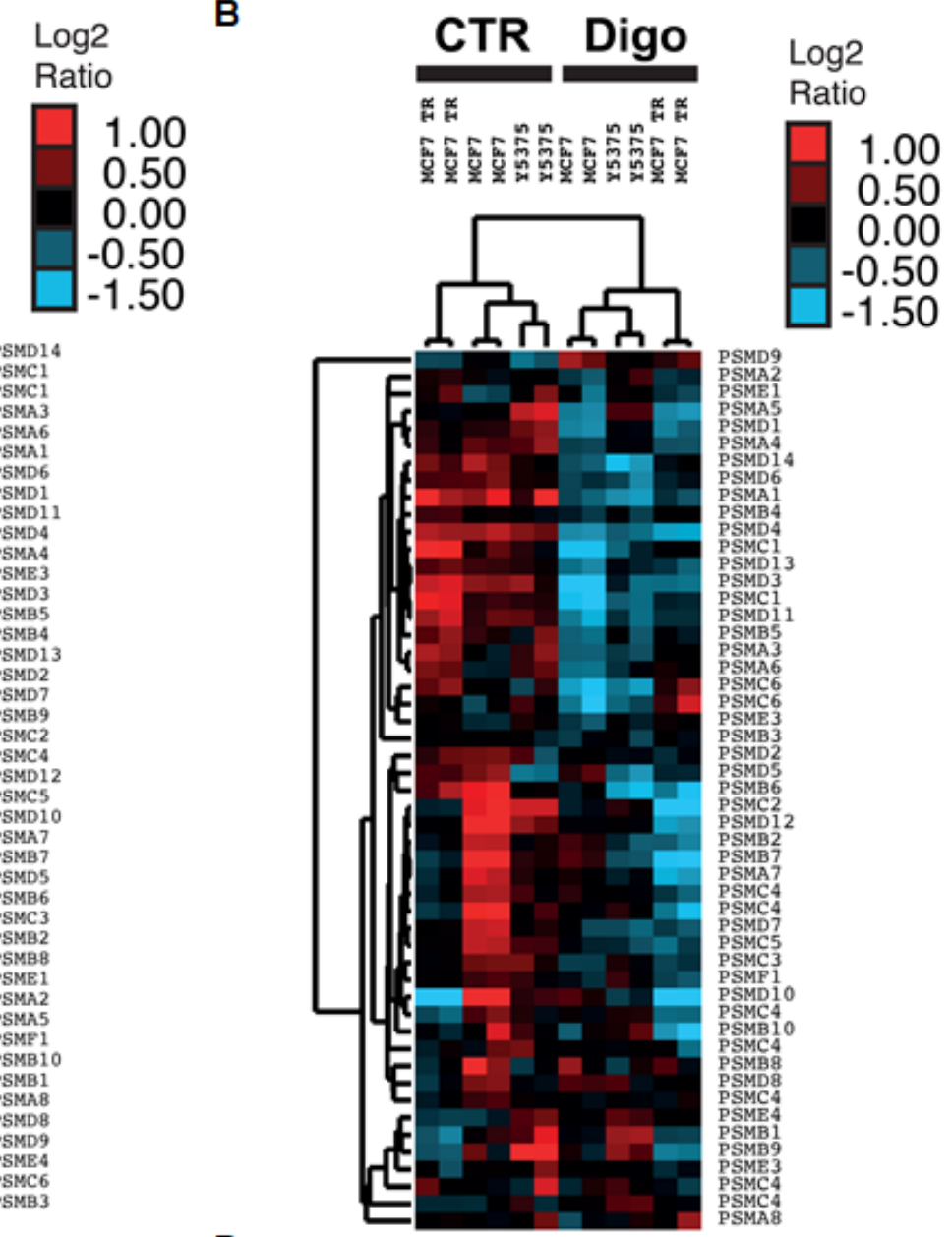

D

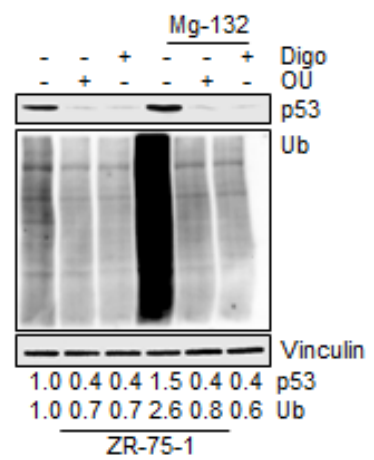

Figure 3. The effects of proteasome genes regulated by ouabain and digoxin on breast cancer cells. Hierarchical clustering analysis of gene expression profiles, relative to $20 \mathrm{~S}$ proteasome-related gene set, in cells treated for $24 \mathrm{~h}$ with OU (A) and Digo (B). Experiments were performed in duplicates. Western blotting analyses of p53, and ubiquitin (Ub) expression in MCF-7 (C) and ZR-75-1 (D) cells treated for $24 \mathrm{~h}$ with ouabain (OU-100 nM) or digoxin (Digo-1000 nM), both in the presence and in the absence (CTR) of the administration of the proteasome inhibitor Mg-132 $(0.5 \mu \mathrm{M})$. All experiments were performed twice in duplicates. The loading control was performed by evaluating vinculin expression in the same filter. 
We observed that treatment with the CGs reduced the total levels of ubiquitinated proteins, as well as the p53 levels in either cell lines, while, as expected, Mg-132 administration to MCF-7 and ZR-75-1 cells effectively increased them (Figure 3C,D). Surprisingly, we additionally observed that both OU and Digo strongly reduced the Mg-132-induced accumulation of both total ubiquitinated species and p53, in both cell lines (Figure 3C,D). Altogether, these results indicate that OU and Digo could alter the homeostasis of the proteasome pathway functions in BC cells.

\subsection{Ouabain and Digoxin-Dependent Activation of the Proteasome}

Prompted by these observations, we hypothesized that the effect of the CGs on the total ubiquitinated species in BC cells could be attributed to their ability to directly affect proteasome activity. To test this hypothesis, we treated MCF10a, ZR-75-1, MCF-7, Y537S, and Tam Res cells with different doses of both OU and Digo for $24 \mathrm{~h}$, and measured all three protease activities of the proteasome (i.e., chymotrypsin-like, caspase-like, and trypsin-like) [27]. In addition, we used the proteasome inhibitor Mg-132 as an internal control for the measurement of proteasome activity [27]. Mg-132 efficiently inhibited all three activities of the proteasome, with an efficacy comparable to previously observed data [27] (Figure 4A', $\mathrm{B}^{\prime}$ and Figure S5). Interestingly, we found that both OU and Digo increased, in a dose-dependent and cell type-specific manner, all the proteasome activities in the cells (Figure 4A,B and Figure S5). In contrast, no change in any of the proteasome activities was detected when non-transformed breast MCF10a cells were treated with different doses of OU and Digo (Figure 4A,B and Figure S5). Therefore, these data suggest that OU and Digo could activate the proteasome in BC cells.

A

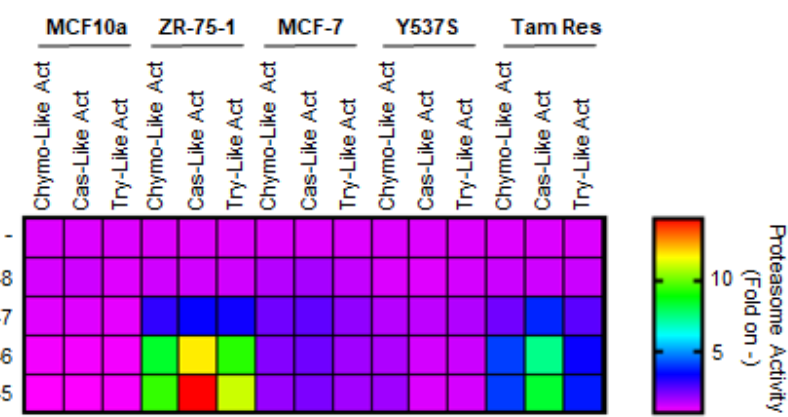

B

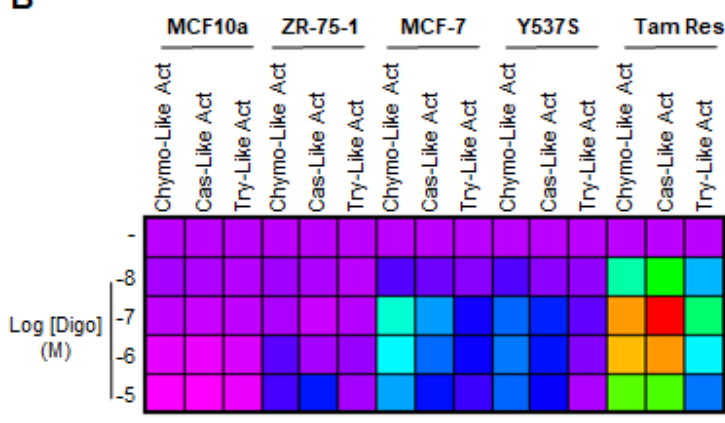

A'

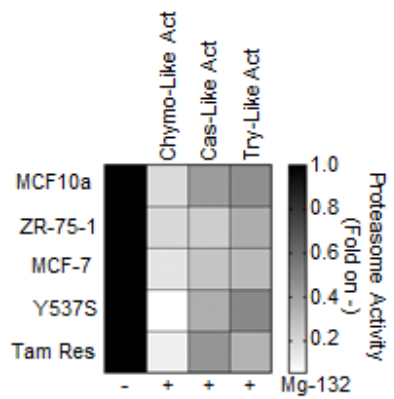

B'

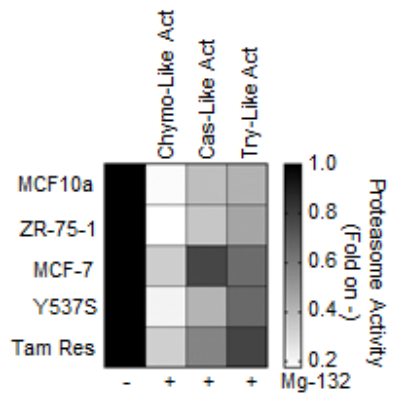

Figure 4. The effect of ouabain and digoxin on proteasome activity in cell lines. Evaluation of the proteasome activities (i.e., chymotrypsin-like, caspase-like, and trypsin-like) in the indicated cell lines, treated for $24 \mathrm{~h}$ with the indicated doses of ouabain (OU) (A) and digoxin (Digo) (B). $\left(\mathbf{A}^{\prime}, \mathbf{B}^{\prime}\right)$ Effect of the proteasome inhibitor Mg-132 (1 $\mu \mathrm{M})$ administered to the tested cells for $24 \mathrm{~h}$ on all three proteasome activities (i.e., chymotrypsin-like, caspase-like, and trypsin-like). All experiments were performed three times, in triplicates. Heatmaps present the mean values. The original data are provided in the source data file, and the graphs are depicted in Figure S5. 
Next, we evaluated whether OU could directly activate the proteasome. For this purpose, we detected in vitro all three protease activities of the proteasome, by administering different doses of both OU and Mg-132 to the recombinant commercially available proteasome. Figure 5A demonstrates that in vitro $\mathrm{OU}$ increased all proteasome activities in a dose-dependent manner, while, as expected, Mg-132 inhibited them (inset in Figure 5A) [27]. Next, we measured the $\mathrm{IC}_{50}$ of Mg-132 for each proteasome activity in the presence of $\mathrm{OU}$, and found that increasing doses of $\mathrm{OU}$ augmented the $\mathrm{IC}_{50}$ of Mg-132 for chymotrypsin-like, caspase-like and tryspin-like activities of the proteasome. A prominent significant effect was observed, especially for the chymotrypsin-like activity (Figure 5B). Thus, OU in vitro competes with the inhibitory activity of the Mg-132 on the recombinant proteasome.

A

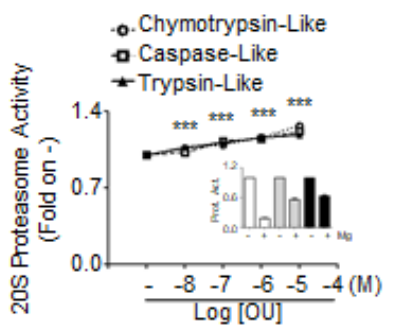

B

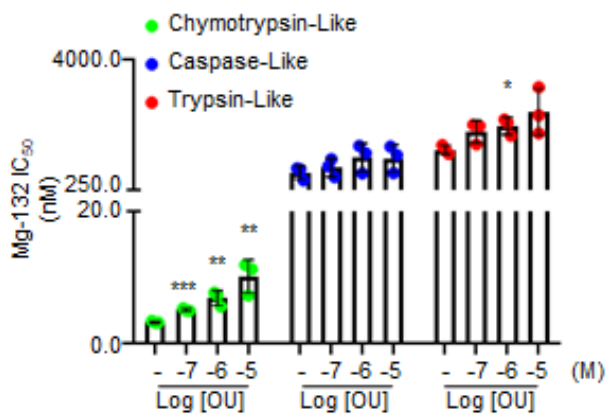

C

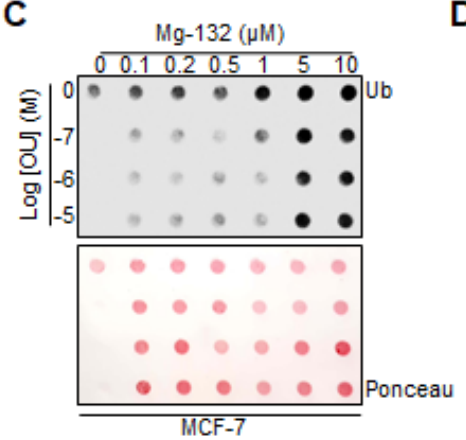

$\mathbf{F}$

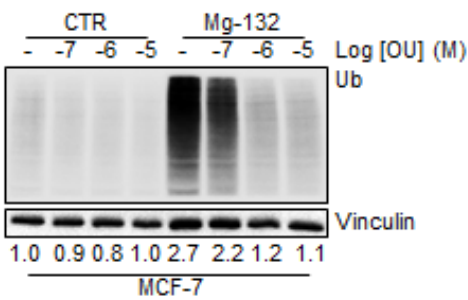

H

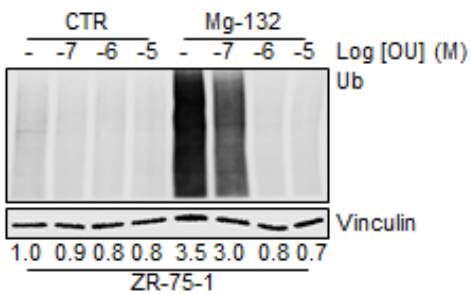

E
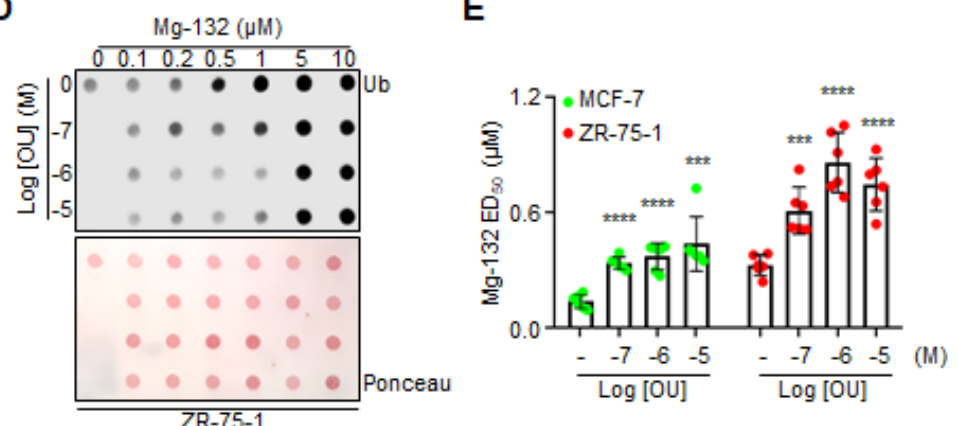

G
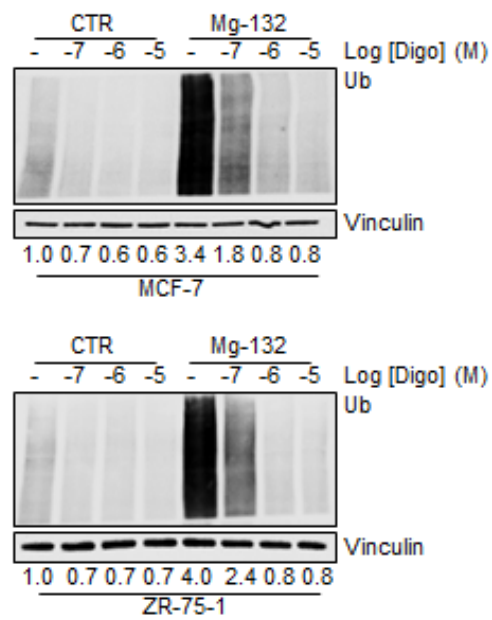

Figure 5. The effect of ouabain and digoxin on proteasome activity in vitro, and in cell lines. (A) In vitro evaluation of the proteasome activities (i.e., chymotrypsin-like, caspase-like, and trypsin-like), using recombinant commercially available $20 \mathrm{~S}$ proteasome, and different doses of ouabain (OU). The inset in panel A indicates the effect of the proteasome inhibitor Mg-132 $(1 \mu \mathrm{M})$ on all three proteasome activities 
(i.e., chymotrypsin-like, caspase-like, and trypsin-like). All experiments were performed three times, in triplicates. Significant differences with respect to the-sample were determined by unpaired two-tailed Student's $t$-test: ${ }^{* * *} p<0.001$ (for all three activities). (B) In vitro evaluation of the inhibitor concentration $50\left(\mathrm{IC}_{50}-\mathrm{nM}\right)$ of the proteasome inhibitor $\mathrm{Mg}-132$ for each proteasome activity (i.e., chymotrypsin-like, caspase-like, and trypsin-like), using recombinant commercially available $20 \mathrm{~S}$ proteasome, both in the presence and in the absence of different doses of ouabain (OU). All experiments were performed three times, in triplicates. Significant differences with respect to the-sample were determined by unpaired two-tailed Student's $t$-test: ${ }^{* *} p<0.001 ;{ }^{* *} p<0.01 ;{ }^{*} p<0.05$. Dot blot of ubiquitin expression (Ub) in MCF-7 (C) and ZR-75-1 (D) cells treated with the indicated doses of both ouabain (OU) and the proteasome inhibitor Mg-132, for $24 \mathrm{~h}$. (E) Quantitation of the effective dose $50\left(\mathrm{ED}_{50}-\mu \mathrm{M}\right)$ of the proteasome inhibitor Mg-132 for ubiquitin (Ub) expression in MCF-7 and ZR-75-1 cells, treated with the indicated doses of ouabain (OU). The experiments were performed twice, in triplicates. Significant differences with respect to the-sample were determined by unpaired two-tailed Student's $t$-test: ${ }^{* * *} p<0.0001 ;{ }^{* * *} p<0.001$. Western blotting analyses of ubiquitin (Ub) expression in MCF-7 and ZR-75-1, treated for $24 \mathrm{~h}$ with the indicated doses of ouabain $(\mathrm{OU})(\mathrm{F}, \mathrm{G})$, and digoxin (Digo) $(\mathbf{H}, \mathbf{I})$, both in the presence and absence of the proteasome inhibitor Mg-132 $(0.5 \mu \mathrm{M})$. Experiments were repeated three times. The loading control was performed by evaluating vinculin expression in the same filter.

We next treated both MCF-7 and ZR-75-1 cells with different doses of Mg-132, both in combination with different doses of $\mathrm{OU}$ for $24 \mathrm{~h}$. We detected $\mathrm{Mg}$-132-induced increase in total ubiquitinated species, which is a marker for proteasome inhibition in cell lines. Dot blot analyses were performed on cell lysates spotted on nitrocellulose, and subsequently stained with anti-Ub antibody. As expected, Mg-132 increased the amount of total ubiquitinated species in cells in a dose-dependent manner (Figure 5C,D), with a calculated $\mathrm{ED}_{50}<0.5 \mu \mathrm{M}$, both for MCF-7 and ZR-75-1 cells (Figure 5E). Interestingly, treatment of the two BC cell lines with OU augmented the ED50 of Mg-132 with regard to the accumulation of ubiquitinated species, in a dose-dependent manner (Figure 5E). Finally, we validated the above-mentioned observations by performing regular Western blotting analyses in MCF-7 and ZR-75-1 cells, treated with different doses of OU and Digo, both in the presence and absence of Mg-132 (1 $\mu \mathrm{M})$, for $24 \mathrm{~h}$. As expected, OU and Digo dose-dependently reduced the total ubiquitinated species in both cell lines, while Mg-132 increased them (Figure 5F-I). Remarkably, OU and Digo treatment reduced the Mg-132-dependent accumulation in cellular ubiquitinated proteins as a function of the administrated dose, both in MCF-7 (Figure 5F,G) and in ZR-75-1 (Figure 5H,I) cells. These data demonstrate that OU and Digo enhance proteasome activity, and directly compete with $\mathrm{Mg}-132$ for the proteasome activity in the cells.

\subsection{Ouabain and Digoxin Impact on E2:ER $\alpha$ Signaling}

$\mathrm{ER} \alpha$ binding assay was performed with different doses of OU, Digo and E2, in order to test whether OU and Digo could directly bind $\mathrm{ER} \alpha$ in vitro.

Only E2 (Figure 6A) was able to displace the fluorescent E2, used as a tracer for the recombinant purified $\mathrm{ER} \alpha$ in vitro, with a measured $\mathrm{IC}_{50}$ (i.e., $\mathrm{K}_{\mathrm{d}}$ ) of approximately $2.9 \mathrm{nM}$, as previously reported [36]. Next, the ER $\alpha$ mRNA levels in MCF-7 cells, treated with OU and Digo for $24 \mathrm{~h}$ were measured, and found not to be modified following CGs administration (Figure 6B). These results indicate that OU and Digo do not bind to ER $\alpha$ in vitro, and do not increase ER $\alpha$ mRNA levels.

Next, on the basis of OU and Digo's observed reduction of the ER $\alpha$ content in BC cells, we tested their effect on ER $\alpha$ function, by evaluating E2 signaling to cell proliferation in MCF-7 and ZR-75-1 cells. ER $\alpha$ is a ligand-induced transcription factor that regulates the expression of diverse genes, both those containing and those not containing the estrogen response element (ERE) in their promoters [2]. Therefore, the effect of CGs on E2-induced ER $\alpha$ transcriptional activity was measured by evaluating the expression of ERE- and non-ERE-containing genes upon E2 treatment. 
As expected, the E2-evoked increase in the intracellular content of ERE- and non-ERE-containing genes (i.e., pS2/TFF1, cathepsin D-CatD, cyclin D1-cyc D1, and Bcl-2) was strongly prevented by both OU and Digo pretreatments, in both MCF-7 (Figure 7A,C) and ZR-75-1 (Figure 7B,D) cells. As expected, $\mathrm{ICI}$ administration to $\mathrm{BC}$ cells also prevented the E2-induced accumulation of the above-mentioned proteins, and both ICI, OU, and Digo treatment reduced ER $\alpha$ intracellular levels (Figure 7A,B) in MCF-7 cells. Notably, E2 was able to induce receptor degradation, both in the absence and in the presence of CG administration to BC cells (Figure 7A-D). These data suggest that CGs reduce E2-induced receptor transcriptional activity.

A

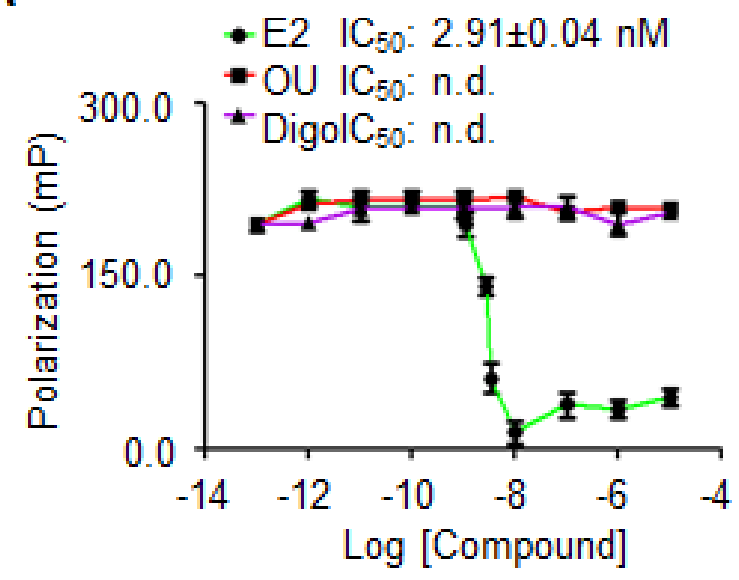

B

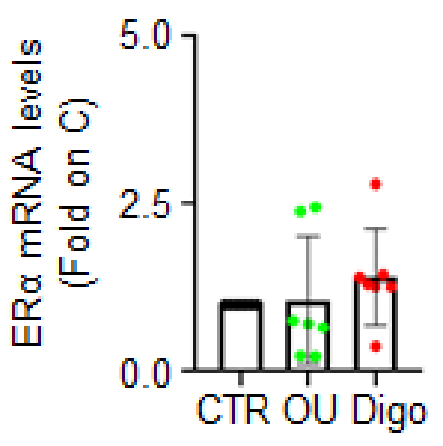

Figure 6. Impact of ouabain and digoxin on ER $\alpha$ binding and mRNA expression. (A) In vitro ER $\alpha$ competitive binding assays for ouabain (OU-red), digoxin (Digo-purple), and 17 $\beta$-estradiol (E2-green) performed at different doses, using a florescent E2 as a tracer. Inhibitor concentration $50\left(\mathrm{IC}_{50}-\mathrm{nM}\right)$ is indicated in the panel, for each compound. The experiment was performed in quintuplicates. (B) Real-time qPCR analysis of ER $\alpha$ mRNA levels in MCF-7 cells, treated for $24 \mathrm{~h}$ with ouabain (OU-100 nM) and digoxin (Digo-100 nM). The experiment was repeated seven times.

In order to substantiate these findings, we directly compared the effect of ICI, OU, and Digo, on two E2-regulated genes (i.e., pS2/TFF1, and CatD), in both MCF-7 and Y537S cells [37]. We chose Y537S cells, since their mutated ER $\alpha$ is a transcriptional hyperactive receptor variant, which assumes a constitutively active agonist structural conformation, identical to that of the wild type (wt) receptor bound to the cognate hormone E2 [15,38]. As shown in Figure 7E,F, pS2/TFF1 and CatD expression was upregulated in Y537S with respect to MCF-7 cells, as previously reported [37]. Interestingly, while treatment of MCF-7 cells with ICI, OU, and Digo barely affected the basal expression levels of the above-indicated genes, their administration into Y537S cells reduced the intracellular concentration of both pS2/TFF1 and CatD (Figure 7E,F). Notably, the observed effect of both OU and Digo in reducing the abundance of pS2/TFF1 and CatD appeared to be superior to that achieved by ICI administration (Figure 7E,F). 
A

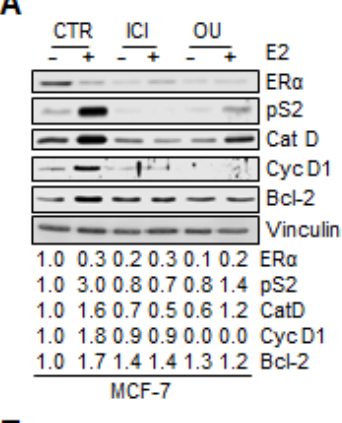

E

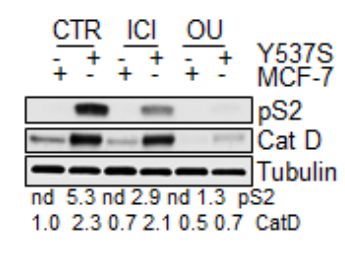

F

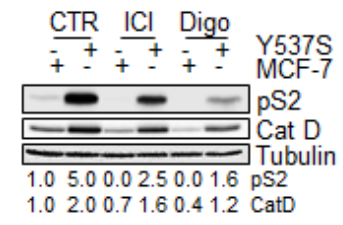

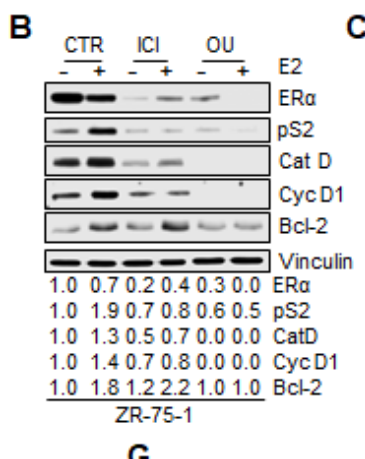

G

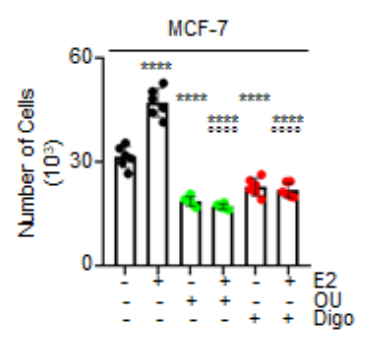

C

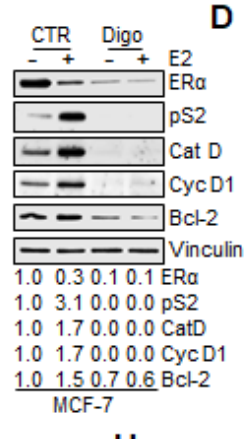

H

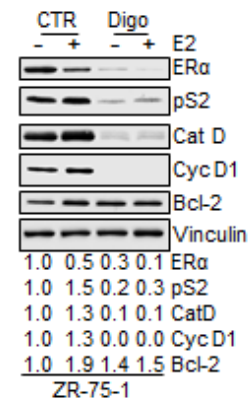

ZR-75-1

Figure 7. The impact of ouabain and digoxin on E2:ER $\alpha$ signaling in breast cancer cells. Western blotting of ER $\alpha$, presenilin-2 (pS2), cathepsin D (Cat D), cyclin D1 (Cyc D1), and Bcl-2 expression in MCF-7 (A), and ZR-75-1 (B) cells, treated, or untreated (CTR) with ouabain (OU-100 nM) or ICI182,780 (ICI-100 nM), in the presence of $17 \beta$-estradiol (E2 $1 \mathrm{nM})$, for $24 \mathrm{~h}$. The loading control was performed by evaluating vinculin expression in each filter. All experiments were performed in triplicates. Western blotting of ER $\alpha$, presenilin-2 (pS2), cathepsin D (Cat D), cyclin D1 (Cyc D1), and Bcl-2 expression in MCF-7 (C), and in ZR-75-1 (D) cells treated, and untreated (CTR) with digoxin (Digo-1000 nM), in the presence of $17 \beta$-estradiol (E2 $1 \mathrm{nM})$, for $24 \mathrm{~h}$. The loading control was performed by evaluating vinculin expression in each filter. All experiments were performed in triplicates. Western blotting of presenilin-2 (pS2), cathepsin D (Cat D), and caveolin-1 (Cav-1) in MCF-7 (E) and Y537S ER $\alpha$-expressing MCF-7 (Y537S) (F) cells, treated, and untreated (CTR) with ouabain (OU-100 nM), digoxin (Digo-1000 nM), or ICI182,780 (ICI-100 nM), for $24 \mathrm{~h}$. The loading control was performed by evaluating tubulin expression in each filter. All experiments were performed twice. Number of MCF-7 (G) and ZR-75-1 (H) cells, treated, and untreated (-) with ouabain (OU-100 nM), or with digoxin (Digo-1000 nM) in the presence of $17 \beta$-estradiol (E2 $1 \mathrm{nM}$ ), for $48 \mathrm{~h}$. Experiments were performed twice, in triplicates. Significant differences with respect to the-sample were determined by unpaired two-tailed Student's $t$-test: ${ }^{* * * *} p<0.0001 ;{ }^{*} p<0.05$. Significant differences with respect to the $17 \beta$-estradiol (E2) sample were determined by unpaired two-tailed Student's $t$-test: ${ }^{\circ 000} p<0.0001$.

The E2-dependent activation of $\mathrm{ER} \alpha$ in BC cells results in cell cycle progression and cell proliferation [2]. In turn, we studied the effect of CGs on the ability of E2 to induce cell proliferation in MCF-7 and ZR-75-1 cells. As expected, E2 induced an increase in cell number after $48 \mathrm{~h}$ of treatment (Figure 7G,H). Pretreatment of BC cell lines with either OU or Digo prevented both the basal and the E2-induced increase in cell number, in both MCF-7 (Figure 7G), and in ZR-75-1 (Figure 7H) cells.

Altogether, these data indicate that treatment of BC cells with CGs prevents E2-induced $\mathrm{ER} \alpha$-dependent transcriptional activity, as well as the ability of E2 to induce cell proliferation. 


\subsection{Ouabain and Digoxin-Dependent Proteasome Activation Precedes the Antiproliferative Effects}

The data we obtained on the effect of OU and Digo on BC cells indicate that they reduce the levels of ER $\alpha$ within $24 \mathrm{~h}$, leading to E2-insensitivity, block the cell cycle in the G2 phase, hyperactivate the proteasome, and induce BC cell death.

Therefore, we sought to determine the chronological succession of the observed effects. We treated the ZR-75-1 cells with OU and Digo for $8 \mathrm{~h}$, and measured ER $\alpha$ and general protein ubiquitination levels and proteasome activity, and performed cell cycle analysis.

Under these conditions, both OU and Digo were able to reduce the cellular levels of ER $\alpha$ and of total ubiquitinated proteins (Figure 8A,D). In addition, after $8 \mathrm{~h}$, while the CGs increased proteasome activity in a dose-dependent manner, and the Mg-132 efficiently inhibited them (Figure 8B,E and relative insets), they did not induce any significant variations in the cell cycle phases (Figure 8C,F).

Therefore, these data suggest that the OU- and Digo-dependent proteasome activation occurs prior to cell cycle block in G2.

A

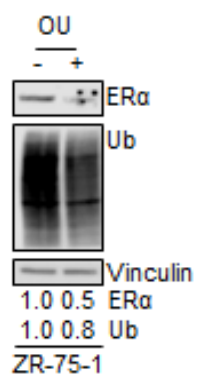

D

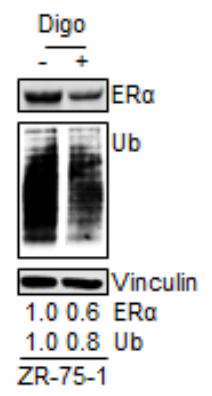

B

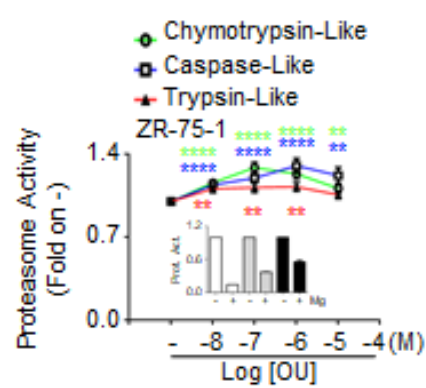

E

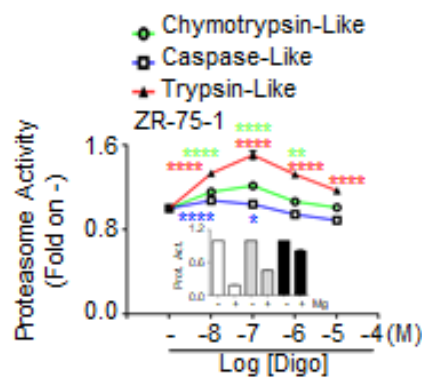

C

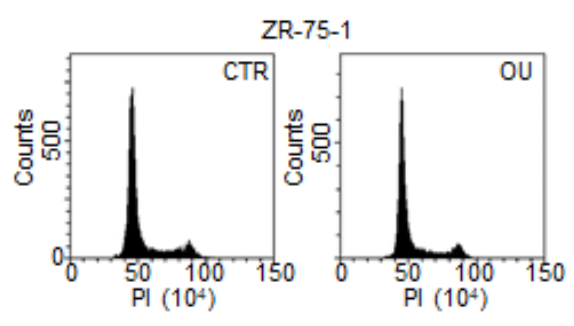

$\mathbf{F}$

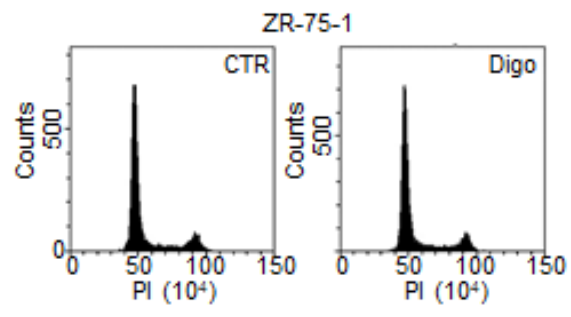

Figure 8. The short-term effect of ouabain and digoxin on ER $\alpha$ expression, proteasome activity, and cell cycle in ZR-75-1 cells. Western blotting analyses of ER $\alpha$ and ubiquitin (Ub) expression in ZR-75-1 cells, treated for $8 \mathrm{~h}$ with ouabain (OU-100 nM) (A), and digoxin (Digo-1000 nM) (D). The loading control was performed by evaluating vinculin expression in the same filter. Experiments were repeated three times. Evaluation of the proteasome activities (i.e., chymotrypsin-like, caspase-like, and trypsin-like) in ZR-75-1 cells, treated for $8 \mathrm{~h}$ with different doses of ouabain (B) and digoxin (E). Insets in panels B-E indicate the effect on all three proteasome activities (i.e., chymotrypsin-like, caspase-like, and trypsin-like) of the proteasome inhibitor Mg-132 (1 $\mu \mathrm{M})$, administered to ZR-75-1 cells for $8 \mathrm{~h}$. All experiments were performed twice, in triplicates. Significant differences with respect to the-sample were determined by unpaired two-tailed Student's $t$-test: ${ }^{* * * *} p<0.0001 ;{ }^{* *} p<0.01$; ${ }^{*} p<0.05$. Cell cycle analyses of ZR-75-1 cells treated for $8 \mathrm{~h}$ with ouabain $(\mathrm{OU}-100 \mathrm{nM})(\mathrm{C})$, and digoxin (Digo-1000 nM) (F). Experiments were repeated three times. 


\subsection{Preclinical Evaluation of Ouabain and Digoxin as Novel Drugs for Treatment of Primary and Metastatic BC}

Since OU and Digo independently exhibit antiproliferative activities in cells modeling primary and metastatic BC, we next evaluated whether they could display synergistic effects with endocrine therapy drugs already used for treatment of primary and metastatic BC.

Therefore, we first treated MCF-7 and ZR-75-1 cells with increasing concentrations of $4 \mathrm{OH}-\mathrm{Tam}$ (10-100,000 nM), OU and Digo (10-100 nM). Combination analyses of both 4OH-Tam with OU or Digo significantly reduced the number of both MCF-7 and ZR-75-1 cells (i.e., cellular models of primary BC) with respect to both untreated, 4OH-Tam-, and OU- and Digo-treated cells (Figure 9A,B). Contrarily, combination analyses in Y537S cells (i.e., a cellular model of MBC) with 4OH-Tam or ICI, and the novel SERDs AZD9496 and GDC-9545 [2,10,39] did not exhibit any combinatorial effects (data not shown). These data indicate that $\mathrm{OU}$ and Digo demonstrate synergism with known anti-BC drugs in preventing cell proliferation, and further suggest that they could be used as an adjuvant drug in the treatment of primary, rather than MBC.

Next, we studied the antiproliferative effects of OU and Digo in MCF-7 and Y537S tumor cell spheroids, also using ICI as internal control. Tumor spheroids were counted at time 0 (i.e., before drug administration), and at the end of the treatment (i.e., 7 days). Both MCF-7 and Y537S cell spheroids grew within the experimental window (i.e., 7 days), and ICI was able to prevent MCF-7, but not Y537S spheroid growth (Figure $9 \mathrm{C}, \mathrm{C}^{\prime}$ ). On the contrary, both OU and Digo reduced the number of MCF-7 and Y537S spheroids (Figure $9 \mathrm{C}, \mathrm{C}^{\prime}$ ). Therefore, these data indicate that $\mathrm{OU}$ and Digo maintain their antiproliferative activity also in a $3 \mathrm{D}$ environment.

Prompted by these results, we additionally studied the ability of the CGs to demonstrate anticancer effects in an in vivo model of a breast tumor. For this purpose, we generated xenograft of Y537S cells in a Zebrafish environment, which is recognized as a reliable cancer model for testing the efficacy of anti-BC drugs [40,41]. Figure 9D shows that treatment of Y537S cell xenograft with OU and Digo resulted in a statistically significant reduction in the primary tumor area after 4 days of treatment, in comparison with untreated control xenografts. Therefore, the CGs reduce tumor mass also in the context of a living organism.

Finally, we investigated whether the OU- and Digo-regulated genes derived by Affymetrix profiling could identify putative OU or Digo responsive patients with $4 \mathrm{OH}$-Tam-resistant human BC. For this purpose, we downloaded gene expression data of a cohort of 177 TCGA-BRCA patients treated with $4 \mathrm{OH}-\mathrm{Tam}$, and the relevant information about treatment response. BC samples were separated into hormone-therapy sensitive (i.e., with a complete response, $C R, N=163$; RECIST criteria), and hormone-therapy resistant (i.e., with progressive disease, PD, $\mathrm{N}=6$; RECIST criteria) samples. We then performed Gene Set Enrichment Analysis (GSEA) of the cohort of BC samples, using the common top 100 upregulated and top 100 downregulated genes by OU or Digo (Tables S1 and S2). Strikingly, we found a significant enrichment (NES $>1.5$; FDR $<5 \%$ ) of the 'top 100 downregulated genes' among the core of upregulated genes in PD patients (Figure 9E). Similar results were obtained in hormone-therapy sensitive (CR) and in hormone-therapy resistant samples, but not for the stable disease samples (SD, $N=8$; RECIST criteria) (Figure 9F). These results suggest that the signature of the overexpressed genes in hormone-resistant patients could be reverted by treatments with OU and Digo.

Overall, these data demonstrate that OU and Digo exert synergistic antiproliferative activity with classic 'anti-estrogen' drugs, work in 3D models of breast tumors, and stratify different classes of patients as potentially responsive to these drugs. 
A

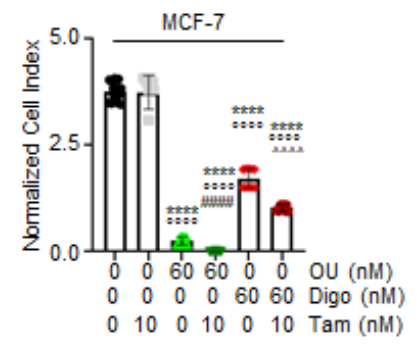

C
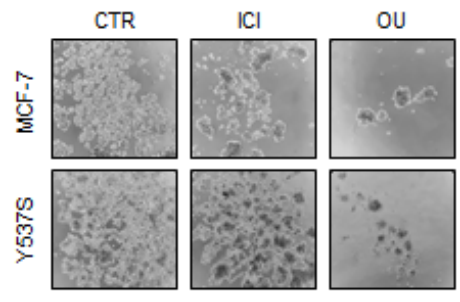

E

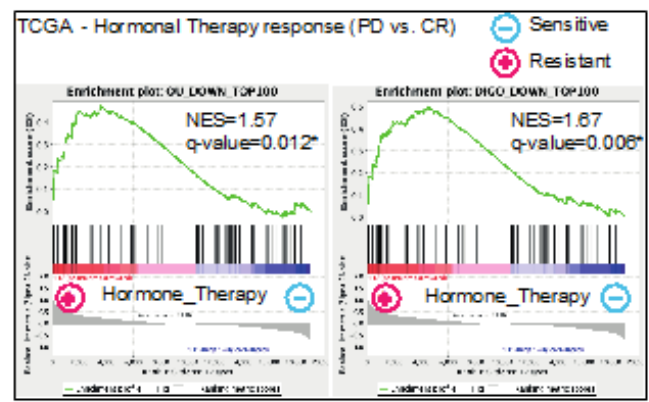

B

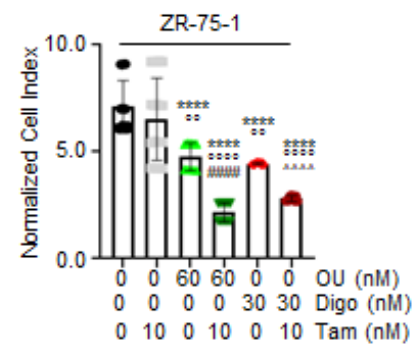

C'

D
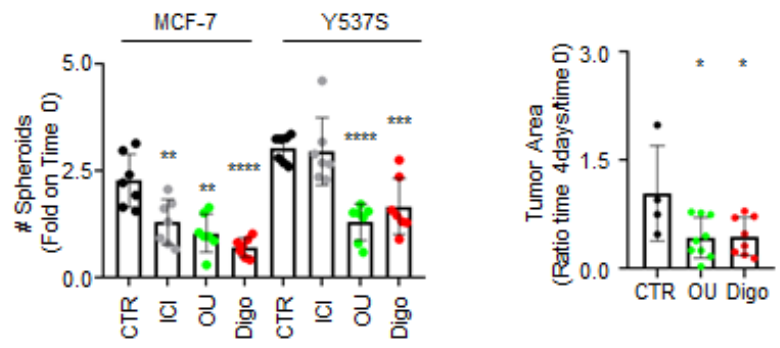

$\mathbf{F}$

Figure 9. The effect of ouabain and digoxin in preclinical models of breast cancer. Normalized cell index (i.e., cell number, as described in Section 2.3) measured in MCF-7 (A), and ZR-75-1 (B) for 5 days, with the combination of the indicated drugs. Significant differences with respect to the 0,0 sample were determined by unpaired two-tailed Student's $t$-test: ${ }^{* * * *} p<0.0001$. Significant differences with respect to the $4 \mathrm{OH}$-Tamoxifen (4OH-TAM) sample were determined by unpaired two-tailed Student's $t$-test: ${ }^{\circ 000} p<0.0001 ;{ }^{\circ 0} p<0.01$. Significant differences with respect to the ouabain (OU) sample were determined by unpaired two-tailed Student's $t$-test: \#\#\# $p<0.0001$. Significant differences with respect to the digoxin (Digo) sample were determined by unpaired two-tailed Student's $t$-test: ${ }^{m \mu} p<0.0001$. Images (C) and quantitation $\left(\mathbf{C}^{\prime}\right)$ of tumor spheroids generated in MCF-7 and Y537S ER $\alpha$-expressing MCF-7 (Y537S), treated at time 0 with ICI182,780 (ICI-100 nM), ouabain (OU-100 nM), digoxin (Digo-100 nM), or left untreated (CTR), for 7 days. Experiments were performed twice, in quadruplicate. Significant differences with respect to the CTR sample were determined by unpaired two-tailed Student's $t$-test: ${ }^{* * * *} p<0.0001$; ${ }^{* * *} p<0.001$; ${ }^{* *} p<0.01$. (D) The effect of DMSO (four fishes were used), $\mathrm{OU}(10 \mu \mathrm{M})$ (nine fishes were used), and Digo $(1.5 \mu \mathrm{M})$ (eight fishes were used) on the tumor area in Zebrafish xenografts of Y537S ER $\alpha$-expressing MCF-7 (Y537S) cells treated for 4 days. Significant differences with respect to the CTR sample were determined by unpaired two-tailed Student's $t$-test: ${ }^{*} p<0.05$. Details are given in Section 2.12. These experiments were performed by ZeClincs. The related final report is available upon request. GSEA analysis of ouabain (OU) and digoxin (Digo) gene sets (i.e., the top 100 downregulated genes) in hormone-resistant patients (PD) vs. complete responders (CR) (E), and vs. stable disease patients (SD) (F) of the TCGA-BRCA cohort. NES, normalized enriched score; $q$-value, significance of enrichment based on 1000 random gene permutations. 


\section{Discussion}

$\mathrm{ER} \alpha$ targeting through specific inhibitor ligands remains paramount in the treatment of primary and metastatic BC [1,2,7-10,42]. However, we and others have also demonstrated that the sole modification of ER $\alpha$ intracellular concentration in BC cells is sufficient to reduce or block cancer cell proliferation, even if $\mathrm{ER} \alpha$ is not directly targeted by the drug $[2,43,44]$. In this respect, we found OU and Digo as FDA-approved drugs that reduce ER $\alpha$ intracellular content and cell proliferation in ductal carcinoma cells (MCF-7 cells), in a previous drug screen [18]. Here, we characterized the effects of these CGs in BC cells, in order to pave the way for their application as an alternative therapeutic strategy for the treatment of primary and/or metastatic BC, either separately, or in combination with classic endocrine therapy drugs.

By using different cellular models mimicking primary and metastatic BCs, we found that OU and Digo induce ER $\alpha$ degradation without binding to $\mathrm{ER} \alpha$, prevent $\mathrm{E} 2 \mathrm{ER} \alpha$-mediated transcriptional activity, and block E2-induced cell proliferation, inducing apoptosis by blocking the cell cycle in the G2 phase, and are small-molecule activators of the proteasome. Time-dependent analysis also suggests that the CGs induce proteasome activation, ER $\alpha$ protein reduction, E2 insensitivity, cell cycle blockade, and apoptosis (Figure 10). Remarkably, the CGs-induced effects are at least partially independent of the inhibition of $\mathrm{Na} / \mathrm{K}$ ATPase, since they occur at concentrations below (or comparable to) the measured $\mathrm{IC}_{50}$ of the $\mathrm{Na} / \mathrm{K}$ pump for each cell line. Moreover, they also occur in ZR-75-1 cells, where OU and Digo do not inhibit $\mathrm{Na} / \mathrm{K}$ ATPase activity $[45,46]$.

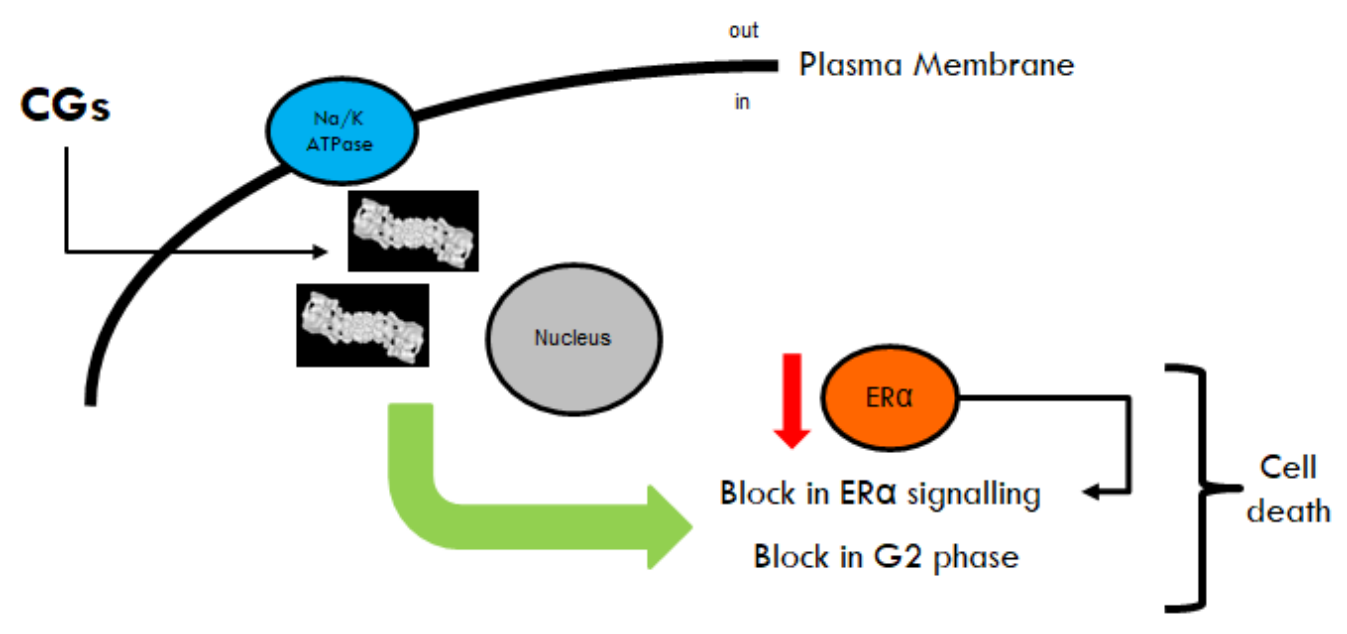

Figure 10. Proposed model for ouabain and digoxin functions in BC cells. Schematic description of the proposed mechanism of ouabain and digoxin (i.e., cardiac glycosides-CGs) in breast cancer cells. A detailed description of the various steps is provided in the main text.

Over the last decade, FDA-approved CGs drugs were demonstrated as effective anticancer drugs [20]. Accordingly, our data confirm the antiproliferative activity of OU and Digo in primary and metastatic BC cell lines. We observed that they block the cell cycle in the G2 phase, and induce apoptosis. OU and Digo work as antiproliferative agents in cellular models of MBC resistant to $4 \mathrm{OH}$-Tam treatment. In addition to ER $\alpha$ degradation, our BC transcriptome analyses provide further evidence to elucidate the antiproliferative effects of these CGs in MBC cells. Indeed, both OU and Digo preferentially reduce the genes in the cholesterol metabolism pathway, by reducing the levels of the transcription factors SREBP1 and SREBP2. Interestingly, it is increasingly recognized that MBC cells appear to be dependent on cholesterol metabolism [47]. Thus, OU and Digo could revert metabolic reprogramming by switching off cholesterol biosynthesis in $\mathrm{MBC}$, causing cell death.

Moreover, IPA analysis shows that OU and Digo could reduce the activity of many transcription factors in which overexpression is required for sustained proliferation and cancer progression (e.g., 
NRF2, SOX11, TBX2) [48-51]. This implies that these CGs could generally impact the transcriptional networks required for sustained cancer progression. In this respect, it is important to point out that the differences in the sensitivity to CGs we observed in Tam Res cells with respect to ER $\alpha$ degradation and cell proliferation could indicate that while on one hand these cells are more resistant to the degradation of the receptor, on the other hand they could be more susceptible to the degradation of unknown critical proteins that regulate cell proliferation.

OU and Digo induce ER $\alpha$ degradation in all tested cell lines, including the one expressing the $\mathrm{ER} \alpha$ Y537S mutated variant, which is resistant to SERD-induced degradation [2]. ER $\alpha$ degradation is not initiated by the direct binding of OU and Digo to the receptor, and not even by an OU- and Digo-dependent reduction in ER $\alpha$ mRNA levels. However, Affymetrix analyses and subsequent experiments demonstrated that OU and Digo are small molecule activators of the proteasome. On this basis, we propose that the CGs-induced proteasome hyperactivity most likely results in the observed CGs-induced ER $\alpha$ degradation.

Measurement of the activities of the proteasome in various cell lines demonstrates that OU and Digo differentially affect the chymotrypsin-like, caspase-like, and trypsin-like activity of the proteasome in a cell-type-dependent manner. Importantly, in our cell-based studies, we additionally report a specificity of OU and Digo in activating the proteasome in BC cells, while the proteasome activity in non-transformed breast cells (i.e., MCF10a) appears barely affected. This is possibly because different proteasome subunit compositions between non-transformed and tumor cell lines could exist. Unfortunately, we were not able to study in vitro the ability of Digo to affect proteasome activity, because its solvent (i.e., DMSO) interferes with in vitro measurements. Nonetheless, in vitro OU increases all three activities of the recombinant commercially available proteasome, and competes with the proteasome inhibitor Mg-132 for the modulation of the proteasome activity. Cellular studies further confirmed these results, and indicated that Digo also exerts such effects on two different BC cell lines. At the present, although the structural biochemical mechanism(s) underlying OU- and Digo-dependent proteasome activation are unknown, in vitro data for OU suggest that these CGs could directly bind to some proteasome subunits, the identification of which would be made possible through bioinformatic analyses (i.e., docking studies).

Competition studies, both in vitro and in cell lines, strongly indicate that OU and Digo can work as allosteric activators of the proteasome, as they interfere with the Mg-132 inhibitor function in the proteasome. In this respect, since $\mathrm{Mg}-132$ has a higher affinity for the chymotrypsin-like activity of the proteasome [27], and OU appears to compete with Mg-132 specifically for this enzymatic function, it is tempting to speculate that OU could bind to the region of the proteasome directly required for chymotrypsin-like activity. Accordingly, the fact that within $24 \mathrm{~h}$, OU and Digo reduce the expression of the proteasome subunit genes, while within $8 \mathrm{~h}$ they induce the activation of the proteasome enzymatic activities, leads us to speculate that cells activate a rapid compensatory mechanism to buffer the CGs-dependent proteasome activation. Interestingly, the ability of OU to activate the proteasome can also explain some of the previously reported effects of this CG on specific components of the ubiquitination pathway [52].

To date, no small molecules that directly activate the proteasome in the nanomolar range are available [53], with the exception of the herein identified OU and Digo. Proteasome activation is being recognized as a therapeutic strategy to treat proteotoxic disorders [54]. Thus, present discoveries render these FDA-approved CGs appealing for the treatment of other pathologies in addition to BC, including some neurological disorders, where the cytosolic accumulation of undegradable proteins is a pathogenetic cause of disease. Accordingly, a similar proteasome activator-based approach has been previously proposed for Huntington's disease [55].

Nonetheless, the present data also suggest caution should be applied in the use of these CGs in normal cells, and disclose the necessity to accurately choose concentrations of OU and Digo, and control their effects on the proteasome during the developmental phase of a CGs-based pharmacological treatment. Indeed, although we demonstrated that OU and Digo do not activate the proteasome 
in a non-transformed cell line, available data show that high proteasome activity relates to cancer development $[56,57]$. However, at the same time, our data strongly indicate that the OU and Digo ability to activate the proteasome is prospective for the treatment of ER $\alpha$-expressing BCs. In this respect, BC patients who were treated with CGs (i.e., digitalis protocol) before being diagnosed with cancer have a significantly lower mortality rate than the patients that did not previously undergo digitalis [58]. Moreover, presently, administration of digitalis drugs is not considered as treatment for women diagnosed with $\mathrm{BC}$, and no clinical studies exist to demonstrate the efficacy of digitalis administration in women with BC. Thus, our results offer a new treatment option for ER $\alpha+B C$ patients, especially because digitalis drugs affect a cellular pathway (i.e., proteasome) that controls ER $\alpha$ abundance, and consequently its activity in BC cells. Such a novel strategy aligns with the concept that in cancers, both strong inhibition and hyperactivation of a specific target are valuable options for therapeutic treatment of the disease [59].

In addition, in the perspective of ER $\alpha+$ breast tumors, it is important to note that OU and Digo block E2 signaling for cell proliferation. Indeed, we observed that they prevent the accumulation of those proteins, whose genes are under the control of the E2-activated ER $\alpha$. More importantly, both OU and Digo are effective in reducing the transcriptional hyperactive E2-mimetic activity of the ER $\alpha$ Y537S mutant. Therefore, OU and Digo strongly reduce ER $\alpha$ transcriptional activity and, in turn, their ability to proliferate in response to E2. Notably, the blockade of E2:ER $\alpha$ transcriptional signaling, and consequently cell proliferation observed for these CGs is similar to the effects elicited by aromatase inhibitors and 4OH-Tam [1], suggesting that these drugs could be useful for the treatment of primary BCs. Notably, OU and Digo preferentially synergize with classic endocrine therapy drugs (e.g., 4OH-Tam) in primary BC cells (see below), indicating that they could be used as adjuvant drugs in the context of a primary breast tumor.

The OU and Digo cardiotoxic effects [20] remain an issue when considering their clinical potentials as anticancer drugs. In this perspective, our analyses have shown that the activation of the proteasome, the reduction in ER $\alpha$ protein levels, and blockade in cell proliferation occur within the nanomolar range, which is compatible with the plasma concentrations achieved in patients treated with FDA-approved doses of the drugs [60]. Nonetheless, our coadministration studies with classic or novel endocrine therapy drugs (i.e., 4OH-Tam, ICI, AZD. and GDC) in cell lines exhibiting primary (i.e., MCF-7 and ZR-75-1 cells) and metastatic BCs (i.e., Y537S cells) reveal that OU and Digo can synergize with endocrine therapy drugs only in primary BC cells. In this respect, it is important to note that the doses of $4 \mathrm{OH}-\mathrm{Tam}, \mathrm{OU}$, and Digo can be efficiently scaled down in the low nanomolar range (i.e., 30-60 nM) to determine a synergic antiproliferative activity. Moreover, OU and Digo maintain their antiproliferative effects at nanomolar concentrations also in a 3D culture model of BC (tumor spheroids), and display antitumor effects in Zebrafish xenografts of MBC cells (i.e., Y537S).

Importantly, we also demonstrated that OU and Digo downregulate genes which are among the most overexpressed in patients with $\mathrm{BC}$ resistant to $4 \mathrm{OH}$-Tam treatment. Although these observations warrant further investigation to explore the efficacy of OU and Digo as an alternative therapeutic strategy for $4 \mathrm{OH}$-Tam-resistant patients, they open the possibility to explore the effect of these drugs as potential additional treatments for $\mathrm{MBC}$, for which a standard therapeutic protocol is still not available. Thus, overall, our present preclinical investigations suggest that OU and Digo could work as effective antiproliferative agents in an organized tumor environment, at nanomolar doses.

\section{Conclusions}

Our discoveries demonstrate that OU and Digo could work in the cellular level as 'anti-estrogen'-like compounds, and provide the basis for further clinical research to evaluate the possibility to reallocate them as drugs for treating primary and metastatic BCs that became insensitive to endocrine therapy drugs. 
Supplementary Materials: The following are available online at http://www.mdpi.com/2072-6694/12/12/3840/s1, Table S1. OU regulated genes, Table S2. DIGO regulated genes, Table S3. Enriched pathways in OU regulated genes, Table S4. Enriched pathways in DIGO regulated genes, Table S5. Enriched upstream modulator in OU regulated genes, Table S6. Enriched upstream modulator in DIGO regulated genes, Table S7. 20S Proteasome subunit genes (Hugo gene nomenclature commetee www.genenames.org). Figure S1. Ouabain- and digoxin-induced $\mathrm{ER} \alpha$ degradation. Figure S2. Ouabain- and digoxin-induced reduction in cell proliferation. Figure S3. Ouabainand digoxin-induced variation in cell cycle. Figure S4. Validation of the ingenuity pathway analysis upstream regulator in breast cancer cells. Figure S5. Ouabain- and digoxin-induced proteasome activation. Source data: the whole blot (uncropped blots) showing all the bands with all molecular weight markers for all the Western blots shown in the figures as well as the raw data for each graph.

Author Contributions: Conceptualization, F.A.; methodology, O.P.; formal analysis, F.B.; investigation, C.B., S.L., M.F., S.B., M.C., and E.M.; writing-original draft preparation, F.A., F.B. and E.M.; writing-review and editing, F.A.; review, F.B.; funding acquisition, F.A. All authors have read and agreed to the published version of the manuscript.

Funding: The research leading to these results has received funding from AIRC under IG 2018-ID. 21325 project and under MFAG-ID. 12756-P.I. Acconcia Filippo. This study was also supported by grants from Ateneo Roma Tre and Fondo di finanziamento per le attività base di ricerca (FFABR) to F.A. The Grant of Excellence Departments, MIUR (ARTICOLO 1, COMMI 314-337 LEGGE 232/2016) to Department of Science, University Roma TRE is also gratefully acknowledged.

Acknowledgments: The authors thank also Simak Ali, University of London Imperial College, England for the gift of the Y537S MCF-7 cells and Carol Dutkowski, University of Cardiff, England for the gift of the 4OH-Tamoxifen resistant MCF-7 cells (Tam Res).

Conflicts of Interest: The authors declare no conflict of interest. The funders had no role in the design of the study; in the collection, analyses, or interpretation of data; in the writing of the manuscript, or in the decision to publish the results.

\section{References}

1. Rugo, H.S.; Rumble, R.B.; Macrae, E.; Barton, D.L.; Connolly, H.K.; Dickler, M.N.; Fallowfield, L.; Fowble, B.; Ingle, J.N.; Jahanzeb, M.; et al. Endocrine Therapy for Hormone Receptor-Positive Metastatic Breast Cancer: American Society of Clinical Oncology Guideline. J. Clin. Oncol. Off. J. Am. Soc. Clin. Oncol. 2016, 34, 3069-3103. [CrossRef]

2. Busonero, C.; Leone, S.; Bartoloni, S.; Acconcia, F. Strategies to degrade estrogen receptor alpha in primary and ESR1 mutant-expressing metastatic breast cancer. Mol. Cell Endocrinol. 2019, 480, 107-121. [CrossRef]

3. Nass, N.; Kalinski, T. Tamoxifen resistance: From cell culture experiments towards novel biomarkers. Pathol. Res. Pract. 2015, 211, 189-197. [CrossRef]

4. Ali, S.; Rasool, M.; Chaoudhry, H.; Pushparaj, N.P.; Jha, P.; Hafiz, A.; Mahfooz, M.; Abdus Sami, G.; Azhar Kamal, M.; Bashir, S.; et al. Molecular mechanisms and mode of tamoxifen resistance in breast cancer. Bioinformation 2016, 12, 135-139. [CrossRef]

5. Nasrazadani, A.; Thomas, R.A.; Oesterreich, S.; Lee, A.V. Precision Medicine in Hormone Receptor-Positive Breast Cancer. Front. Oncol. 2018, 8, 144. [CrossRef]

6. Rondon-Lagos, M.; Villegas, V.E.; Rangel, N.; Sanchez, M.C.; Zaphiropoulos, P.G. Tamoxifen Resistance: Emerging Molecular Targets. Int. J. Mol. Sci. 2016, 17, 1357. [CrossRef]

7. Fanning, S.W.; Jeselsohn, R.; Dharmarajan, V.; Mayne, C.G.; Karimi, M.; Buchwalter, G.; Houtman, R.; Toy, W.; Fowler, C.E.; Han, R.; et al. The SERM/SERD bazedoxifene disrupts ESR1 helix 12 to overcome acquired hormone resistance in breast cancer cells. eLife 2018, 7. [CrossRef]

8. Toy, W.; Weir, H.; Razavi, P.; Lawson, M.; Goeppert, A.U.; Mazzola, A.M.; Smith, A.; Wilson, J.; Morrow, C.; Wong, W.L.; et al. Activating ESR1 Mutations Differentially Affect the Efficacy of ER Antagonists. Cancer Discov. 2017, 7, 277-287. [CrossRef]

9. Zhao, Y.; Laws, M.J.; Guillen, V.S.; Ziegler, Y.; Min, J.; Sharma, A.; Kim, S.H.; Chu, D.; Park, B.H.; Oesterreich, S.; et al. Structurally Novel Antiestrogens Elicit Differential Responses from Constitutively Active Mutant Estrogen Receptors in Breast Cancer Cells and Tumors. Cancer Res. 2017, 77, 5602-5613. [CrossRef]

10. Joseph, J.D.; Darimont, B.; Zhou, W.; Arrazate, A.; Young, A.; Ingalla, E.; Walter, K.; Blake, R.A.; Nonomiya, J.; Guan, Z.; et al. The selective estrogen receptor downregulator GDC-0810 is efficacious in diverse models of ER+ breast cancer. eLife 2016, 5. [CrossRef] 
11. Martin, L.A.; Ribas, R.; Simigdala, N.; Schuster, E.; Pancholi, S.; Tenev, T.; Gellert, P.; Buluwela, L.; Harrod, A.; Thornhill, A.; et al. Discovery of naturally occurring ESR1 mutations in breast cancer cell lines modelling endocrine resistance. Nat. Commun. 2017, 8, 1865. [CrossRef]

12. Bahreini, A.; Li, Z.; Wang, P.; Levine, K.M.; Tasdemir, N.; Cao, L.; Weir, H.M.; Puhalla, S.L.; Davidson, N.E.; Stern, A.M.; et al. Mutation site and context dependent effects of ESR1 mutation in genome-edited breast cancer cell models. Breast Cancer Res. BCR 2017, 19, 60. [CrossRef]

13. Li, Z.; Levine, K.M.; Bahreini, A.; Wang, P.; Chu, D.; Park, B.H.; Oesterreich, S.; Lee, A.V. Upregulation of IRS1 enhances IGF1 response in Y537S and D538G ESR1 mutant breast cancer cells. Endocrinology 2018, 159, 285-296. [CrossRef]

14. Mao, C.; Livezey, M.; Kim, J.E.; Shapiro, D.J. Antiestrogen Resistant Cell Lines Expressing Estrogen Receptor alpha Mutations Upregulate the Unfolded Protein Response and are Killed by BHPI. Sci. Rep. 2016, 6, 34753. [CrossRef]

15. Harrod, A.; Fulton, J.; Nguyen, V.T.M.; Periyasamy, M.; Ramos-Garcia, L.; Lai, C.F.; Metodieva, G.; de Giorgio, A.; Williams, R.L.; Santos, D.B.; et al. Genomic modelling of the ESR1 Y537S mutation for evaluating function and new therapeutic approaches for metastatic breast cancer. Oncogene 2017, 36, 2286-2296. [CrossRef]

16. Pernas, S.; Tolaney, S.M.; Winer, E.P.; Goel, S. CDK4/6 inhibition in breast cancer: Current practice and future directions. Adv. Med. Oncol. 2018, 10. [CrossRef]

17. Busonero, C.; Leone, S.; Acconcia, F. Emetine induces estrogen receptor alpha degradation and prevents 17beta-estradiol-induced breast cancer cell proliferation. Cell. Oncol. 2017. [CrossRef]

18. Busonero, C.; Leone, S.; Klemm, C.; Acconcia, F. A functional drug re-purposing screening identifies carfilzomib as a drug preventing 17beta-estradiol: ERalpha signaling and cell proliferation in breast cancer cells. Mol. Cell. Endocrinol. 2018, 460, 229-237. [CrossRef]

19. Leone, S.; Busonero, C.; Acconcia, F. A high throughput method to study the physiology of E2:ERalpha signaling in breast cancer cells. J. Cell. Physiol. 2018, 233, 3713-3722. [CrossRef]

20. Botelho, A.F.M.; Pierezan, F.; Soto-Blanco, B.; Melo, M.M. A review of cardiac glycosides: Structure, toxicokinetics, clinical signs, diagnosis and antineoplastic potential. Toxicon 2019, 158, 63-68. [CrossRef]

21. Mijatovic, T.; Van Quaquebeke, E.; Delest, B.; Debeir, O.; Darro, F.; Kiss, R. Cardiotonic steroids on the road to anti-cancer therapy. Biochim. Biophys. Acta 2007, 1776, 32-57. [CrossRef]

22. Knowlden, J.M.; Hutcheson, I.R.; Jones, H.E.; Madden, T.; Gee, J.M.; Harper, M.E.; Barrow, D.; Wakeling, A.E.; Nicholson, R.I. Elevated levels of epidermal growth factor receptor/c-erbB2 heterodimers mediate an autocrine growth regulatory pathway in tamoxifen-resistant MCF-7 cells. Endocrinology 2003, 144, 1032-1044. [CrossRef]

23. Rotroff, D.M.; Dix, D.J.; Houck, K.A.; Kavlock, R.J.; Knudsen, T.B.; Martin, M.T.; Reif, D.M.; Richard, A.M.; Sipes, N.S.; Abassi, Y.A.; et al. Real-time growth kinetics measuring hormone mimicry for ToxCast chemicals in T-47D human ductal carcinoma cells. Chem. Res. Toxicol. 2013, 26, 1097-1107. [CrossRef]

24. Cipolletti, M.; Leone, S.; Bartoloni, S.; Busonero, C.; Acconcia, F. Real-time measurement of E2: ERalpha transcriptional activity in living cells. J. Cell. Physiol. 2020. [CrossRef]

25. Di Veroli, G.Y.; Fornari, C.; Wang, D.; Mollard, S.; Bramhall, J.L.; Richards, F.M.; Jodrell, D.I. Combenefit: An interactive platform for the analysis and visualization of drug combinations. Bioinformatics 2016, 32, 2866-2868. [CrossRef]

26. Riccardi, C.; Nicoletti, I. Analysis of apoptosis by propidium iodide staining and flow cytometry. Nat. Protoc. 2006, 1, 1458-1461. [CrossRef]

27. Kisselev, A.F.; Goldberg, A.L. Proteasome inhibitors: From research tools to drug candidates. Chem. Biol. 2001, 8, 739-758. [CrossRef]

28. Fiske, C.H.; Subbarow, Y. The Colorimetric Determination of Phosphorus. J. Biol. Chem. 1925, 66, 375-400.

29. Bartoloni, S.; Leone, S.; Acconcia, F. Unexpected Impact of a Hepatitis C Virus Inhibitor on 17beta-Estradiol Signaling in Breast Cancer. Int. J. Mol. Sci. 2020, 21, 3418. [CrossRef]

30. Froehlich, K.; Haeger, J.D.; Heger, J.; Pastuschek, J.; Photini, S.M.; Yan, Y.; Lupp, A.; Pfarrer, C.; Mrowka, R.; Schleussner, E.; et al. Generation of Multicellular Breast Cancer Tumor Spheroids: Comparison of Different Protocols. J. Mammary Gland Biol. Neoplasia 2016, 21, 89-98. [CrossRef]

31. Cornet, C.; Dyballa, S.; Terriente, J.; Di Giacomo, V. ZeOncoTest: Refining and Automating the Zebrafish Xenograft Model for Drug Discovery in Cancer. Pharmaceuticals 2019, 13, 1. [CrossRef] [PubMed] 
32. Yang, Y.; Kitagaki, J.; Dai, R.M.; Tsai, Y.C.; Lorick, K.L.; Ludwig, R.L.; Pierre, S.A.; Jensen, J.P.; Davydov, I.V.; Oberoi, P.; et al. Inhibitors of ubiquitin-activating enzyme (E1), a new class of potential cancer therapeutics. Cancer Res. 2007, 67, 9472-9481. [CrossRef]

33. Pesiri, V.; Totta, P.; Marino, M.; Acconcia, F. Ubiquitin-activating enzyme is necessary for 17beta-estradiol-induced breast cancer cell proliferation and migration. Iubmb Life 2014, 66, 578-585. [CrossRef] [PubMed]

34. Maspero, E.; Mari, S.; Valentini, E.; Musacchio, A.; Fish, A.; Pasqualato, S.; Polo, S. Structure of the HECT:ubiquitin complex and its role in ubiquitin chain elongation. EMBO Rep. 2011, 12, 342-349. [CrossRef] [PubMed]

35. Love, I.M.; Shi, D.; Grossman, S.R. p53 Ubiquitination and proteasomal degradation. Methods Mol. Biol. 2013, 962, 63-73. [CrossRef]

36. Pesiri, V.; La Rosa, P.; Stano, P.; Acconcia, F. Identification of an estrogen receptor alpha non-covalent ubiquitin binding surface: Role in 17beta-estradiol-induced transcriptional activity. J. Cell Sci. 2013, 126, 2577-2582. [CrossRef]

37. Busonero, C.; Leone, S.; Bianchi, F.; Acconcia, F. In silico screening for ER $\alpha$ downmodulators identifies thioridazine as an anti-proliferative agent in primary, 4OH-tamoxifen-resistant and Y537S ER $\alpha$-expressing breast cancer cells. Cell. Oncol. 2018. [CrossRef]

38. Katzenellenbogen, J.A.; Mayne, C.G.; Katzenellenbogen, B.S.; Greene, G.L.; Chandarlapaty, S. Structural underpinnings of oestrogen receptor mutations in endocrine therapy resistance. Nat. Rev. Cancer 2018, 18, 377-388. [CrossRef]

39. Weir, H.M.; Bradbury, R.H.; Lawson, M.; Rabow, A.A.; Buttar, D.; Callis, R.J.; Curwen, J.O.; de Almeida, C.; Ballard, P.; Hulse, M.; et al. AZD9496: An Oral Estrogen Receptor Inhibitor That Blocks the Growth of ER-Positive and ESR1-Mutant Breast Tumors in Preclinical Models. Cancer Res. 2016, 76, 3307-3318. [CrossRef]

40. Sun, Y.; Sheng, Z.; Ma, C.; Tang, K.; Zhu, R.; Wu, Z.; Shen, R.; Feng, J.; Wu, D.; Huang, D.; et al. Combining genomic and network characteristics for extended capability in predicting synergistic drugs for cancer. Nat. Commun. 2015, 6, 8481. [CrossRef]

41. White, R.; Rose, K.; Zon, L. Zebrafish cancer: The state of the art and the path forward. Nat. Rev. Cancer 2013, 13, 624-636. [CrossRef]

42. Robinson, D.R.; Wu, Y.M.; Vats, P.; Su, F.; Lonigro, R.J.; Cao, X.; Kalyana-Sundaram, S.; Wang, R.; Ning, Y.; Hodges, L.; et al. Activating ESR1 mutations in hormone-resistant metastatic breast cancer. Nat. Genet. 2013, 45, 1446-1451. [CrossRef]

43. Acconcia, F.; Fiocchetti, M.; Marino, M. Xenoestrogen regulation of ERalpha/ERbeta balance in hormone-associated cancers. Mol. Cell. Endocrinol. 2016. [CrossRef]

44. Nassa, G.; Salvati, A.; Tarallo, R.; Gigantino, V.; Alexandrova, E.; Memoli, D.; Sellitto, A.; Rizzo, F.; Malanga, D.; Mirante, T.; et al. Inhibition of histone methyltransferase DOT1L silences ERalpha gene and blocks proliferation of antiestrogen-resistant breast cancer cells. Sci. Adv. 2019, 5, eaav5590. [CrossRef]

45. Hirano, T.; Fukuoka, K.; Oka, K.; Naito, T.; Hosaka, K.; Mitsuhashi, H.; Matsumoto, Y. Antiproliferative activity of mammalian lignan derivatives against the human breast carcinoma cell line, ZR-75-1. Cancer Investig. 1990, 8, 595-602. [CrossRef]

46. Schaefer, T.L.; Lingrel, J.B.; Moseley, A.E.; Vorhees, C.V.; Williams, M.T. Targeted mutations in the Na,K-ATPase alpha 2 isoform confer ouabain resistance and result in abnormal behavior in mice. Synapse 2011, 65, 520-531. [CrossRef]

47. Simigdala, N.; Gao, Q.; Pancholi, S.; Roberg-Larsen, H.; Zvelebil, M.; Ribas, R.; Folkerd, E.; Thompson, A.; Bhamra, A.; Dowsett, M.; et al. Cholesterol biosynthesis pathway as a novel mechanism of resistance to estrogen deprivation in estrogen receptor-positive breast cancer. Breast Cancer Res. BCR 2016, 18, 58. [CrossRef]

48. Cheng, X.; Li, J.; Guo, D. SCAP/SREBPs are Central Players in Lipid Metabolism and Novel Metabolic Targets in Cancer Therapy. Curr. Top. Med. Chem. 2018, 18, 484-493. [CrossRef]

49. Wu, S.; Lu, H.; Bai, Y. Nrf2 in cancers: A double-edged sword. Cancer Med. 2019, 8, 2252-2267. [CrossRef]

50. Yang, Z.; Jiang, S.; Lu, C.; Ji, T.; Yang, W.; Li, T.; Lv, J.; Hu, W.; Yang, Y.; Jin, Z. SOX11: Friend or foe in tumor prevention and carcinogenesis? Adv. Med. Oncol. 2019, 11, 1758835919853449. [CrossRef] 
51. Liu, X.; Miao, Z.; Wang, Z.; Zhao, T.; Xu, Y.; Song, Y.; Huang, J.; Zhang, J.; Xu, H.; Wu, J.; et al. TBX2 overexpression promotes proliferation and invasion through epithelial-mesenchymal transition and ERK signaling pathway. Exp. Med. 2019, 17, 723-729. [CrossRef] [PubMed]

52. Jun, D.W.; Hwang, M.; Kim, H.J.; Hwang, S.K.; Kim, S.; Lee, C.H. Ouabain, a cardiac glycoside, inhibits the Fanconi anemia/BRCA pathway activated by DNA interstrand cross-linking agents. PLoS ONE 2013, 8, e75905. [CrossRef]

53. Huang, L.; Chen, C.H. Proteasome regulators: Activators and inhibitors. Curr. Med. Chem. 2009, 16, 931-939. [CrossRef] [PubMed]

54. Njomen, E.; Tepe, J.J. Proteasome Activation as a New Therapeutic Approach to Target Proteotoxic Disorders. J. Med. Chem. 2019, 62, 6469-6481. [CrossRef] [PubMed]

55. Seo, H.; Sonntag, K.C.; Kim, W.; Cattaneo, E.; Isacson, O. Proteasome activator enhances survival of Huntington's disease neuronal model cells. PLoS ONE 2007, 2, e238. [CrossRef] [PubMed]

56. Astakhova, T.M.; Morozov, A.V.; Erokhov, P.A.; Mikhailovskaya, M.I.; Akopov, S.B.; Chupikova, N.I.; Safarov, R.R.; Sharova, N.P. Combined Effect of Bortezomib and Menadione Sodium Bisulfite on Proteasomes of Tumor Cells: The Dramatic Decrease of Bortezomib Toxicity in a Preclinical Trial. Cancers 2018, 10, 351. [CrossRef] [PubMed]

57. Shashova, E.E.; Lyupina, Y.V.; Glushchenko, S.A.; Slonimskaya, E.M.; Savenkova, O.V.; Kulikov, A.M.; Gornostaev, N.G.; Kondakova, I.V.; Sharova, N.P. Proteasome functioning in breast cancer: Connection with clinical-pathological factors. PLoS ONE 2014, 9, e109933. [CrossRef]

58. Stenkvist, B. Cardenolides and cancer. Anti-Cancer Drugs 2001, 12, 635-638.

59. Wang, L.; Yu, Y.; Chow, D.C.; Yan, F.; Hsu, C.C.; Stossi, F.; Mancini, M.A.; Palzkill, T.; Liao, L.; Zhou, S.; et al. Characterization of a Steroid Receptor Coactivator Small Molecule Stimulator that Overstimulates Cancer Cells and Leads to Cell Stress and Death. Cancer Cell 2015, 28, 240-252. [CrossRef]

60. Andersson, K.-E.; Bergdahl, B. Cardiac Glycosides. In Pharmacokinetics and Clinical Pharmacology; Springer: Berlin/Heidelberg, Germany, 1981.

Publisher's Note: MDPI stays neutral with regard to jurisdictional claims in published maps and institutional affiliations.

(C) 2020 by the authors. Licensee MDPI, Basel, Switzerland. This article is an open access article distributed under the terms and conditions of the Creative Commons Attribution (CC BY) license (http://creativecommons.org/licenses/by/4.0/). 